\title{
Local Information Processing in Dendritic Trees: Subsets of Spines in Granule Cells of the Mammalian Olfactory Bulb
}

\author{
Thomas B. Woolf, ${ }^{1}$ Gordon M. Shepherd, ${ }^{1}$ and Charles A. Greer ${ }^{1,2}$ \\ Sections of 'Neurobiology and 'Neurosurgery, Yale University School of Medicine, New Haven, Connecticut 06510
}

\begin{abstract}
The anaxonic granule cell of the olfactory bulb is believed to inhibit mitral and tufted cells through reciprocal dendrodendritic synapses. However, little is known about the detailed input-output properties of the granule cell. This study explores the functional properties of granule cells by using detailed reconstructions of Golgi-impregnated granule cells as the basis for computational models. Three Golgi-impregnated granule cells from the olfactory bulbs of C57BL/6j mice were selected for detailed analysis. Measurements were made of the diameter and length of all spine heads, spine necks, and dendritic branches. These measurements formed the basis of a compartmental model of each cell in which simulations of the spread of synaptic potentials within the dendritic tree were performed with SABER (Analogy, Inc.), a circuit analysis program. The results show that the degree of spread of synaptic potentials can define functionally related subsets of spines within the dendritic tree. The size of these subsets varies with the anatomical location of the input spine, the magnitude of the input, the time course of the input, the size of the spine neck resistance, and the activity of other spines. The data indicate that the functional organization of granule cell dendritic arbors is more complex than previously thought: between the level of the individual spine and the entire dendritic tree are several levels of subsets of spines that can mediate discrete localized inhibition onto subsets of mitral or tufted cell secondary dendrites within the external plexiform layer of the olfactory bulb.
\end{abstract}

The anaxonic granule cell of the mammalian olfactory bulb offers an interesting model system in which to analyze how electrical properties of dendritic spines and dendritic arbors contribute to the integrative properties of the neuron. Three types of granule cells have been identified on morphological grounds in the mouse (Greer, 1987). Each cell type has a relatively small population of spines that participate in reciprocal dendrodendritic synapses with the dendrites of mitral and tufted cells in the external plexiform layer (EPL; Greer, 1987; Mori, 1987). Physiological and anatomical evidence (Rall et al., 1966; Price and Powell, 1970a,b; Jackowski et al., 1978; Jahr and

\footnotetext{
Received Aug. 1, 1990; revised Jan. 18, 1991; accepted Jan. 24, 1991.

We wish to express appreciation for the excellent technical expertise provided by Christine Kaliszewski, Heather Cameron, and Jarema Malicki and for technical services support for SABER provided by Analogy, Inc. This research was supported by NIDCD Grants DC-00210 to C.A.G., NS-10174 to C.A.G. and G.M.S., and DC-00086 to G.M.S. and by Office of Naval Research Grant N-00014 to G.M.S.

Correspondence should be addressed to Charles A. Greer, Section of Neurosurgery, Yale University School of Medicine, 333 Cedar Street, New Haven, CT 06510.

Copyright (C) 1991 Society for Neuroscience $0270-6474 / 91 / 111837-18 \$ 03.00 / 0$
}

Nicoll, 1982) has indicated that these spines mediate the inhibition of mitral and tufted cells seen in electrophysiological recordings.

The role of the individual spine in relation to the entire set of spines on a granule cell is an issue important to understanding the organization of the granule cell local circuits. For example, are all of the output granule cell spines activated every time one spine receives an EPSP? How do the anatomical location and the individual morphology of a spine influence the output properties of the cell? Answers to these questions are crucial for understanding the role of granule cells and local circuits in processing odor information. A computational study based upon complete anatomical reconstructions at the light microscopic level was undertaken to gain insight into these questions and to generate hypotheses for experimental testing. The aim was to address the role of the granule cell in mediating inhibition by (1) simulating the siting of inputs to spines in many different locations throughout the dendritic tree, (2) examining the transients in other spines and the soma of the cell, (3) varying the time course and strength of the synaptic inputs, (4) changing the dimensions of the spine neck, and (5) varying the value of the membrane resistance, $R_{m}$.

\section{Materials and Methods}

Anatomical procedures. C57BL/6j mice (Jackson Labs, Bar Harbor, Maine) 25-30 d postnatal were employed. Mice were given $70 \mathrm{mg} / \mathrm{kg}$ of pentobarbital intraperitoneally and then perfused through the heart with $0.9 \%$ saline followed by $1 \%$ glutaraldehyde and $1 \%$ paraformal dehyde in $0.1 \mathrm{M}$ phosphate buffer for approximately $15 \mathrm{~min}$ at $0.1 \mathrm{ml} /$ sec. Following perfusion, animals were kept on ice for several hours prior to dissection. A modification of the Golgi-Kopsch procedure was used to impregnate neurons (Riley, 1979; Greer, 1987). In brief, following $3 \mathrm{~d}$ of postfixation at $4^{\circ} \mathrm{C}$, the tissue was immersed in the dichromate solution $(3.5 \mathrm{gm}$ potassium dichromate, $15 \mathrm{gm}$ sucrose, and $1.65 \mathrm{ml} \mathrm{37 \%}$ formalin in $100 \mathrm{ml}$ distilled water) for $5 \mathrm{~d}$ at room temperature. The tissue was then rinsed three times ( 10 sec each) in $0.75 \%$ silver nitrate before being placed in a fresh silver nitrate solution for 24 $\mathrm{hr}$ at room temperature. The tissue was cut coronally at $100 \mu \mathrm{m}$ with a vibratome. The sections were dehydrated through $100 \%$ ethanol, clcared in xylene, and coverslipped with Permount.

Data collection. The tissue was examined at $100 \times$ and $200 \times$ magnification. Based upon the preliminary assessment, over 30 cells were reconstructed with camera lucida at $1000 \times$ oil immersion. From this smaller sample, three granule cells were chosen for detailed morphometric analysis. The principal criteria used in making these choices were that the cell must be completely impregnated with silver, well isolated in the EPL, and free from any interference due to artifacts.

Two different procedures were used to collect detailed morphological information. In the photographic procedure, approximately 300 photomicrographs were taken in a through-focus study with a $100 \times$ oilimmersion lens and printed at a final magnification of $5000 \times$. Measurements of dendritic branch length and diameter and of spine head and spine neck length and diameter were made only over the portions of the photograph that were in focus. The depth of focus at this magnification is $0.2 \mu \mathrm{m}$, allowing an accurate 3-D morphometric image of 

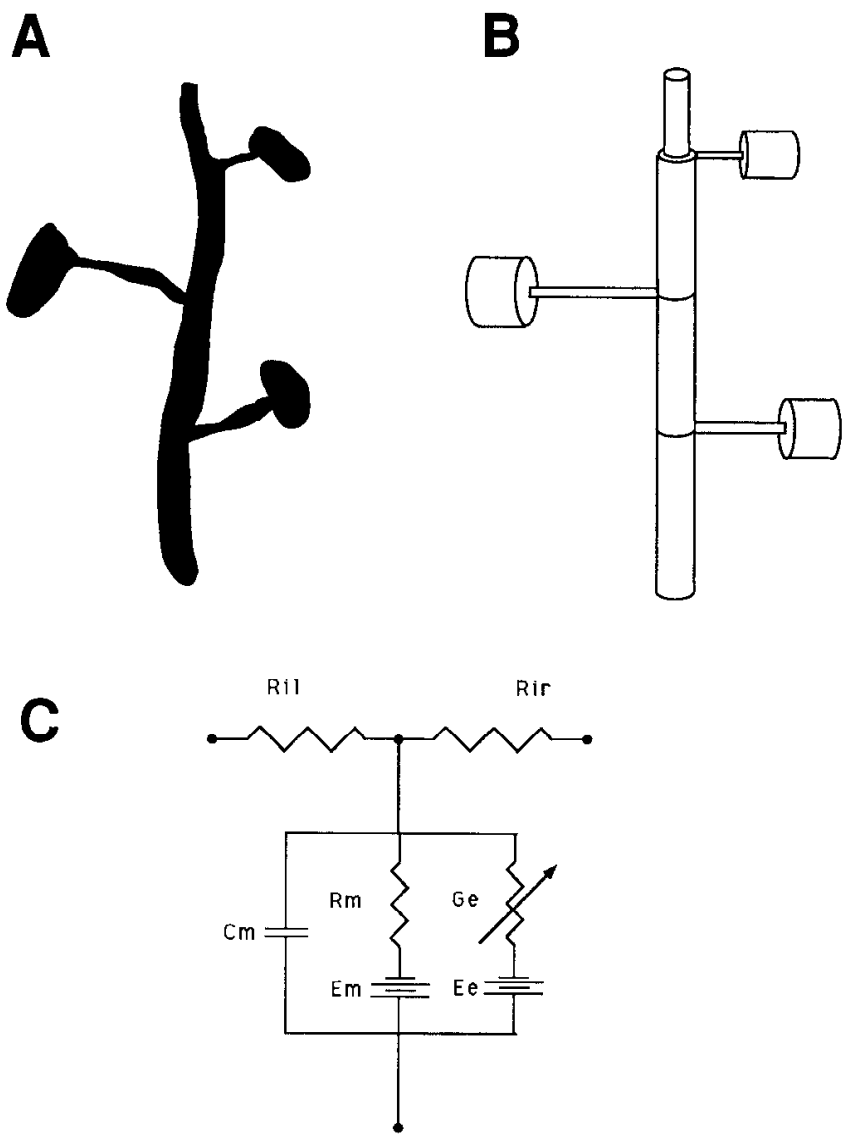

Figure 1. Summary of the construction of electrical circuits from the anatomical measurements. $A$ shows an idealized section of a granule cell from a Golgi impregnation. $B$ presents this same section as a series of electrically connected cylindrical sections. In $C$, the electrical components of each cylinder represented in $B$ are shown.

the cell to be obtained. In the second procedure, a computer imaging system (MCID, Imaging Research Inc.) was used in conjunction with the $100 \times$ oil-immersion lens. Using this system a digitized image was viewed with a video monitor for a final working magnification of $6500 \times$. The digitized image was then used for determining morphometric characteristics with the image analysis software.

Computational methods. Electrical simulations used the compartmental extension of cable theory (Rall, 1964, 1977). The following conventions were employed to convert the anatomical characteristics of the granule cells into electrical compartments: first, it is usually assumed, though it is not required, that the cytoplasmic resistance $\left(R_{i}\right)$, membrane resistance $\left(R_{m}\right)$, and membrane capacitance $\left(C_{m}\right)$ are of uniform value throughout the cell (Rall, 1977). Each cytoplasmic resistance in and out of an individual compartment $\left(R_{l}\right)$ is given by

$$
R_{i}=2 \cdot R_{i} \cdot \frac{l}{\pi \cdot d^{2}},
$$

where the length $(l)$ is of the entire compartment of diameter $d$ (both in $\mathrm{cm}$ ) and $R_{i}$ is estimated at $70 \Omega \cdot \mathrm{cm}$ (Rall, 1977). The membrane resistance of an individual compartment $\left(R_{M}\right)$ is given by

$$
R_{M}=\frac{R_{m}}{\pi \cdot d \cdot l} \text {. }
$$

The value of $R_{m}$ may vary in different cells and species. A value of 4000 $\Omega \cdot \mathrm{cm}^{2}$ has been used in previous simulations of mitral and granule cell dendrites in the rat olfactory bulb (Shepherd and Brayton, 1979). In the turtle, a value of up to $50,000 \Omega \cdot \mathrm{cm}^{2}$ has been estimated from electrophysiological recordings from mitral cells (Mori et al., 1984). For the present models, we have assumed an initial value of $10,000 \Omega \cdot \mathrm{cm}^{2}$ and have explored a range from 1000 to $100,000 \Omega \cdot \mathrm{cm}^{2}$. The individual compartmental capacitance $\left(C_{M}\right)$ is given by

$$
C_{M}=\pi \cdot C_{m} \cdot 1 \cdot \mathrm{d}
$$

where $C_{m}$ is usually taken as $1 \mu \mathrm{F} / \mathrm{cm}^{2}$.

Each compartment was assumed to be capable of synaptic input or current input, though for any given simulation most such inputs were turned off, with only the input or inputs under consideration turned on. Many of the transient simulations used a synaptic conductance $\left(G_{s}\right)$ generated by an $\alpha$ function input with peak magnitude $\left(G_{p}\right)$ of either 1 or $4 \mathrm{nS}$ and a time to peak ( $\left.t_{p}\right)$ of $0.2 \mathrm{msec}$ (see Rall, 1977):

$$
G_{s}=\frac{e \cdot G_{p} \cdot t}{t_{p}} e^{-I / t_{p}}
$$

where $e$ is natural logarithmic base and $t$ is time.

Figure 1 summarizes the connection between the anatomical methods and the electrical model. Figure $1 A$ shows an idealized short stretch of a Golgi-impregnated granule cell, $B$ shows this same segment as a series of cylindrical compartments, and $C$ shows that each compartment consists of the electrical components whose geometry-dependent values were determined as described above.

A circuit simulation program, SABER (Analogy, Inc.), was used for all computations reported in this article. SARER is well suited for these analyses because (1) nonlinear circuit components can be easily written into the simulator; (2) the program is layered so that each usage does not require extensive rewriting of the lower circuit levels: the top levcl, containing connectivity and dimensions, is the only part needing change from one simulation to another; (3) exploring a range of values for dimensions, input locations and magnitudes, and $R_{m}$ changes can be performed with simple commands in a batch file; (4) it is faster than SPICE, a widely available simulation program (Segev et al., 1985) and, with batch files, is capable of many simulations in a 24-hr period. (The use of SABER for neuronal simulations is explained in detail in Carnevale et al., 1990.) Each transient simulation of a dendritic tree with up to 600 compartments took about $90 \mathrm{~min}$ to run on a Sun 3/160 workstation.

\section{Results}

\section{Description of the cells}

The anaxonic granule cell of the olfactory bulb has a small somal diameter of $6-10 \mu \mathrm{m}$ and is found densely packed in the granule cell layer (GCL) of the olfactory bulb. A single apical dendrite ascends into the EPL, where it arborizes and participates in reciprocal dendrodendritic synapses with the secondary dendrites of mitral and tufted cells (Price and Powell, 1970a,b; Jackowski et al., 1978). Several short basal dendrites, restricted to the GCL, may also be present. In mice (and rabbit), three subpopulations of granule cells have been identified on morphological grounds (Mori et al., 1983; Greer, 1987; Mori, 1987). In type I granule cells, the dendritic arbor branches and has spines present throughout the EPL. Presumably, this type I cell synapses with both mitral and tufted cells. Type II granule cells have branching patterns that are confined to the lower one-half to one-third of the EPL, and these cells are believed to synapse mainly with mitral cells and displaced mitral cells near the mitral cell layer (MCL). Type III granule cells arborize extensively only in the upper one-half to one-third of the EPL and are believed to synapse mainly with tufted cells. In the mouse, type II granule cell somata are deep in the GCL, type III granule cell somata are more superficial in the GCL, and the somata of type I cells can be found throughout the GCL (Greer, 1987).

The three cells chosen for the computational modeling exhibited the three main types of dendritic branching patterns described above. Figure 2 shows photomicrographs of Grl, a cell with a branching pattern closest to that of the type I granule cell: spines are distributed throughout a dendritic tree that extends across the entire EPL. For this cell, the soma is within the MCL, and the main dendritic arbor changes into three sec- 

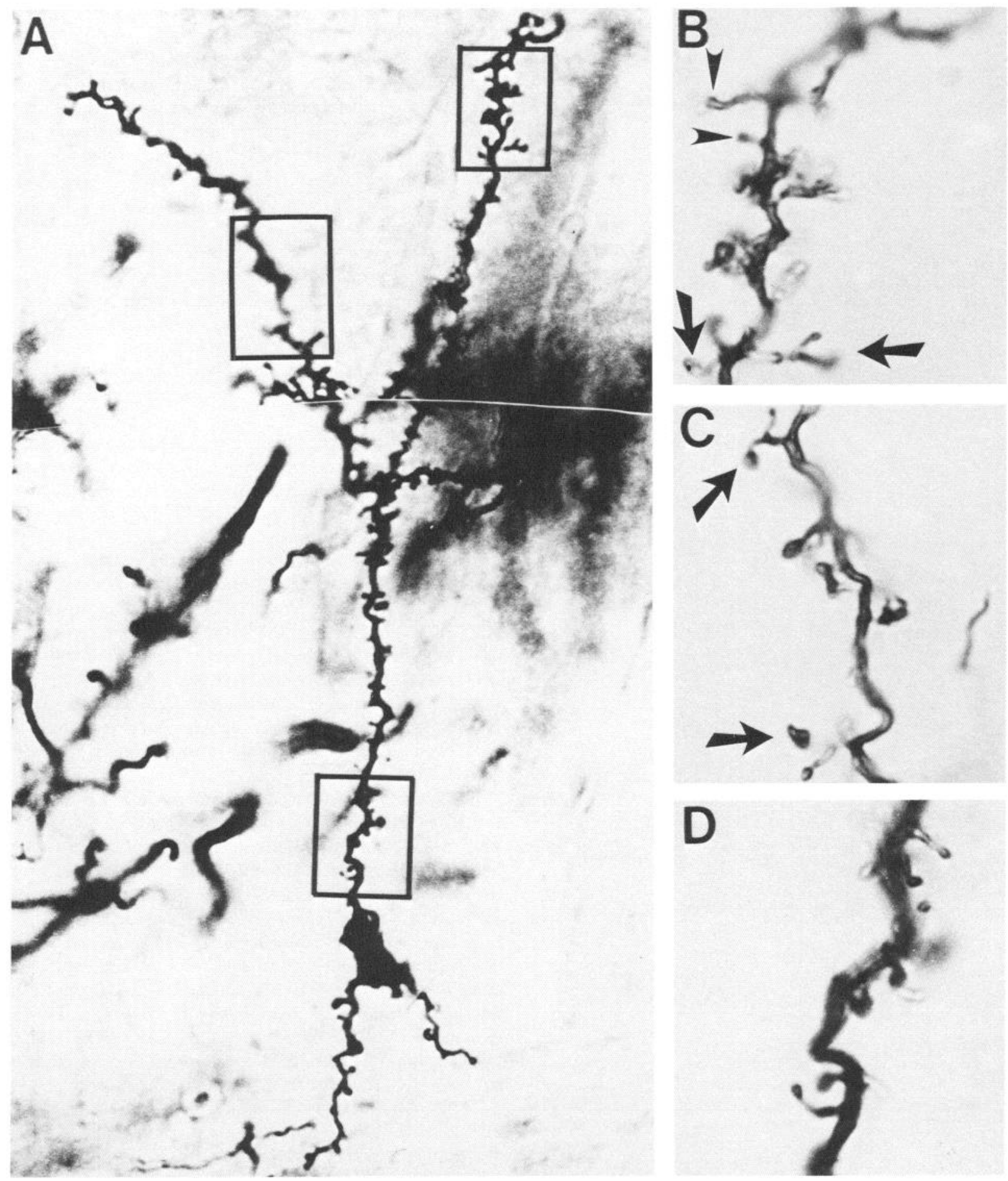

D

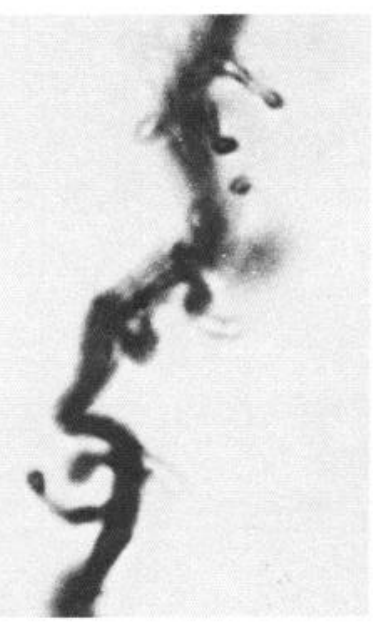

Figure 2. Granule cell Gr1. In $A$ is shown a photomontage of the entire cell. The cell body is in the MCL, and the apical dendrites are near the glomerular layer. $B-D$ are higher-magnification views of the boxed areas in $A$. Notice in $B$ and $C$ the doubly branched spines that are indicated by the curved arrows and, in $B$, the range of morphologies exhibited by spines as illustrated by the arrowheads. Magnification: $A, 700 \times ; B-D, 3000 \times$ ).

ondary branches at a point roughly halfway across the EPL. The soma has two small basal dendrites that extend into the GCL.

Three selected segments of Gr1 are shown at a higher magnification in Figure 2, $B-D$. Notice the presence in both $B$ and $C$ of doubly branched spines (arrows) and the wide range of spine morphologies. For example, note the long, thin spine in the middle of Figure $2 B$ in contrast to the shorter spine immediately below (arrowheads).

The method of constructing the cable representation for each cell is illustrated by considering the transformation of Figure $2 B$ into a cable model in Figure 3. The measured dimensions of all spine necks, spine heads, and dendritic trunk elements 
A

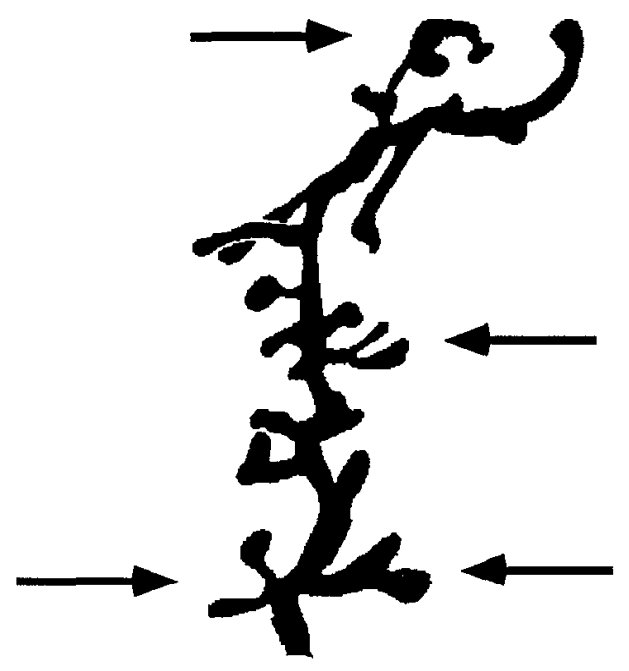

B

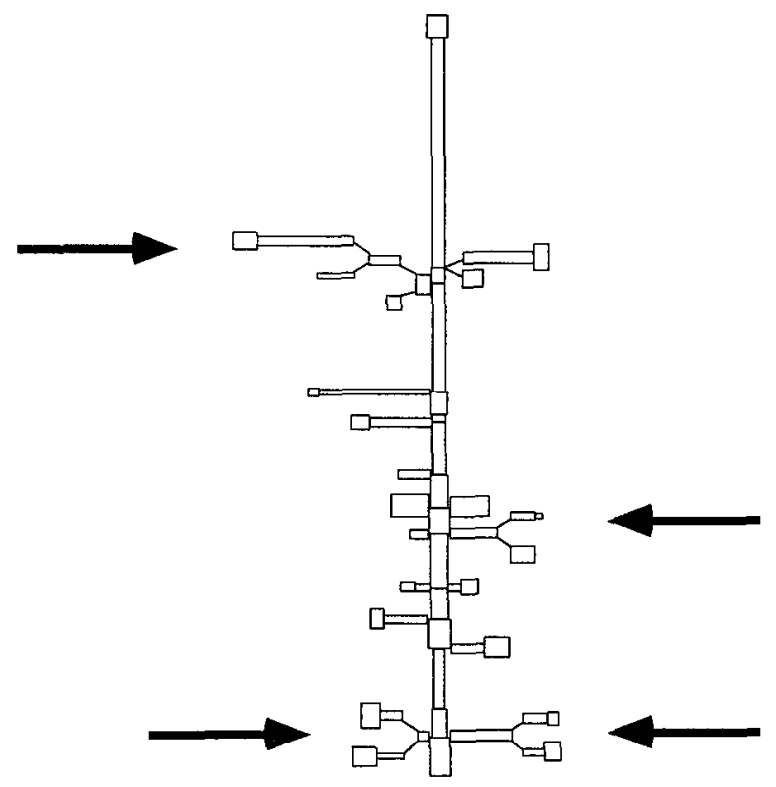

Figure 3. Camera lucida reconstruction of Figure $1 B(A)$ and its transformation into a cable representation $(B)$. Notice the branched spines in $A$ and $B$ and the diversity of spine neck length and spine head size throughout. The camera lucida drawings were made as a guide to the overall morphology, and the cable representations are from a careful through-focus study at higher magnification, so there is not always a 1:1 mapping from drawing to cable representation. Arrows denote corresponding points in $A$ and $B$.

were converted into a series of connected electrical compartments as indicated in the cable model drawing in Figure $3 B$. Notice in particular how the camera lucida representation in Figure $3 A$ is transformed into a series of different-sized compartments in the cable representation in $B$. It should also be noted that new spines and different dimensions may appear in the cable representations of this article than in the camera lucida drawings. This is because the cable models represent information collected from a careful 3-D reconstruction of each cell at $5000 \times$ or $6500 \times$, whereas the camera lucida drawings were made as a guide to the overall morphology of each cell at $1000 \times$.
A complete representation of $\mathrm{Gr} 1$ is shown in Figure 4. Figure $4 A$ shows the camera lucida reconstruction of the cell; $B$ shows a cable model of this cell where each spine and branch element was constructed as in Figure 3. The labeled spines represent sites of possible input for the computational results that follow below. There were 297 total spines on this cell. Of this total, 194 were pedunculated spines, 66 were sessile spines, and 37 were multiply branched spines. In the cable model drawing, the solid diagonal lines connecting branches are an illustrative convenience and do not represent actual cytoplasm. Thus, the branches containing SH87, SH187, and SH247 all join at the main branch near SH77. Furthermore, in the cable model the elaborate 3-D shape of the dendritic arbor has been idealized as a connected set of cylindrical elements. From an electrical standpoint, the two are equivalent because the electrical voltages and currents depend on cytoplasmic distance and membrane surface area, which are correctly incorporated into the cable representation.

Comparable reconstructions were made for two other granule cells. A camera lucida drawing and cable representation of a type II granule cell, Gr2, are shown in Figure 5. The apical tip of the dendritic arbor for Gr2 is about halfway across the EPL, and a branching point occurs in the main dendrite just after the arbor crosses the MCL. Notice that the most apical dendritic branch splits into two small branches that run parallel to each other before terminating. Basal dendrites are present, and the cell soma is relatively deep in the GCL. This cell had 118 pedunculated spines, 25 sessile spines, and 15 multiply branched spines. It was not uncommon to see two spines at nearly the same location on the dendritic arbor and then some distance before the next spines. This irregular local distribution of spines may be important functionally and will be discussed further below.

In Figure 6 a camera lucida drawing and cable model of a type III granule cell, Gr3, are shown. The dendritic tree branches midway across the EPL, with the majority of spines on the upper half of the dendritic arbor. Further branchings occur in two of the secondary branches, and two tertiary branches run together for a considerable distance in the upper EPL. There were 144 total spines on this cell, of which 114 were pedunculated, 6 sessile, and 24 multiply branched. For all three cells, there was considerable tapering of the dendritic trunk from 1.0-1.2 $\mu \mathrm{m}$ near the soma to $0.4-0.6 \mu \mathrm{m}$ in the more distal regions. Figures 4-6, each containing a camera lucida drawing and cable model representation, are useful in interpreting the computational results and may be referred to throughout this article.

The reconstruction of the entire dendritic tree for all three cells contains an enormous amount of information relevant to structure-function relations within these cells. Because each spine is potentially an individual input-output unit, linked to other spines through the intervening dendritic branches, the geometrical relations between spines are critical in controlling the extent to which they interact. Each of the three cells had a unique distribution of spines both with respect to overall distance from the soma and within smaller local regions of the dendritic tree. In Figure $7 A$, the distance of pedunculated spines from the soma is represented for all three cells. It can be seen that Gr1 has more of its spines near the soma than does either Gr2 or Gr3. $\mathrm{Gr} 3$, with most of its spines more than $280 \mu \mathrm{m}$ from the soma, has the majority of its spines at the greatest distance of the three cells. Gr2 is intermediate in its distribution of spines. In Figure $7, B$ and $C$, the variations in the local distributions of spines 


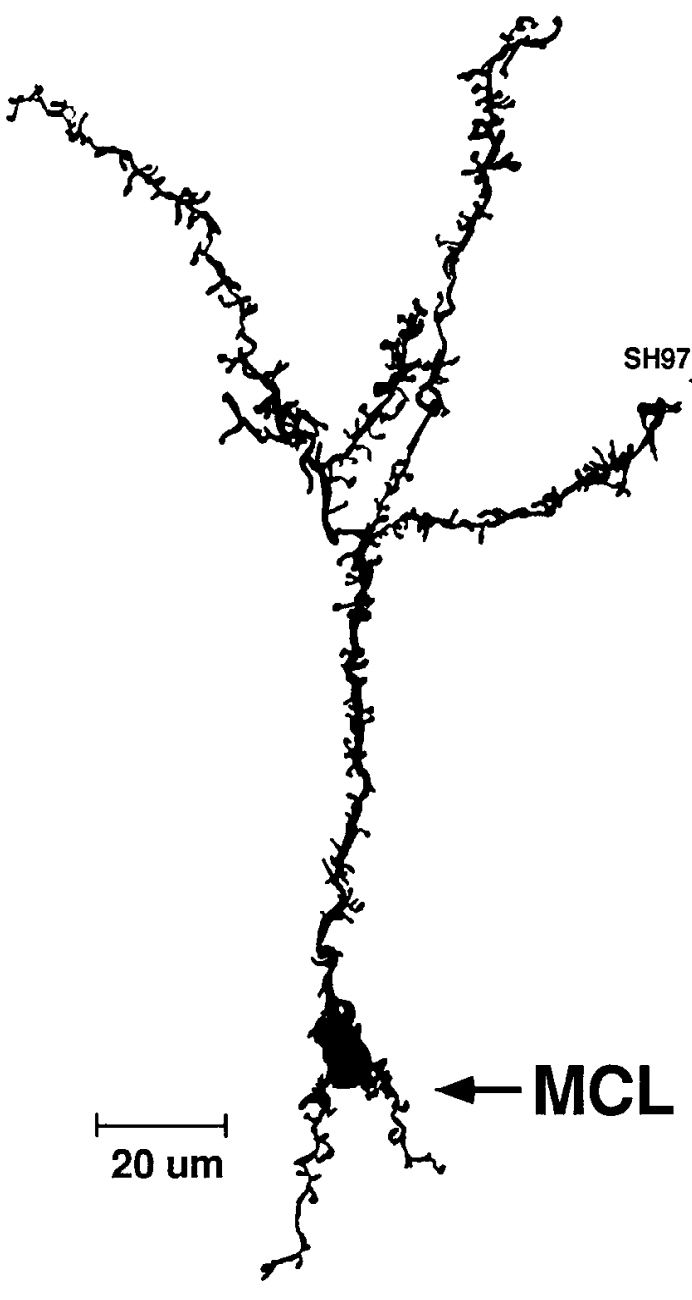

A
B
Figure 4. A camera lucida drawing and cable representation of $\mathrm{Grl}$. $A$ is a camera lucida drawing where the cell body is in the MCL and the apical dendrites reach across the EPL, making this a type I granule cell. The labeled spines in the cable representation of $B$ are sites of synaptic input for the computational modeling. are presented. For all three cells, the first near neighbor to any spine is less than $0.5 \mu \mathrm{m}$ away on average. For $\mathrm{Gr} 1$, the second nearest neighbor is more than $1 \mu \mathrm{m}$ removed, and for $\mathrm{Gr} 2$ and Gr3, more than $2 \mu \mathrm{m}$ and $3 \mu \mathrm{m}$, away, respectively. This emphasizes that the spines are not equally distributed on the dendritic arbor.

An average pedunculated spine as seen in the light microscope on each of these three cells has a spine neck length of $1.9 \mu \mathrm{m}$ and a diameter of $0.4 \mu \mathrm{m}$. The spine head appeared on average as a sphere $0.8 \mu \mathrm{m}$ in diameter. However, the light microscope has a resolution limitation in accurately measuring pedunculated spine neck diameters (Wilson et al., 1983). The initial computations used the original measured value of the spine neck diameter. A second series of computations was performed using a smaller value for the spine neck diameter to compensate conservatively for any overestimate of spine dimensions that may have occurred with the light microscopic measurements.

\section{Computational results}

Intracellular recordings from granule cells have proven to be difficult, and there are as yet no experimentally reliable values for the input resistance or time constant for these cells (Mori and Kishi, 1982; Wellis and Scott, 1989). Patch-clamp determinations of $R_{m}$ may yield significantly higher values than previously suggested from intracellular recordings (Firestein and Werblin, 1987; Coleman and Miller, 1989). Consequently, $\boldsymbol{R}_{m}$ was varied from 1000 to $100,000 \Omega \cdot \mathrm{cm}^{2}$ in the simulations presented in this article. Table 1 shows the variation in the input resistance and time constant for all three model cells for simulated current inputs to the soma. It is interesting that for low $R_{m}$ there is variation in the input resistance, while for higher $R_{m}$, the three cell models are similar. In contrast, the time constants are the same for all three models at a given $R_{m}$ value. To explore further the difference in input resistance between the Gr1 and Gr3 models, current was injected immediately apical to the soma, and the percent of current flowing back to the soma versus apically was computed in the steady state. For Gr1 the percent flowing apically was just above $80 \%$ for all $R_{m}$ values. This was in contrast to $\mathrm{Gr} 3$, where the amount of current flowing apically increased from $54 \%$ to $69 \%$ to $93 \%$ as $R_{m}$ was increased from 1000 to 10,000 to $100,000 \Omega \cdot \mathrm{cm}^{2}$. This suggests that the cellular morphology has a larger impact on the input resistance 
Figure 5. Camera lucida drawing and cable representation for $\mathrm{Gr} 2$. The cell body is relatively deep in the GCL, and the dendrites reach approximately halfway across the EPL, making this a type II granule cell. The labeled spines in $B$ represent possible synaptic input locations for the electrical computations.

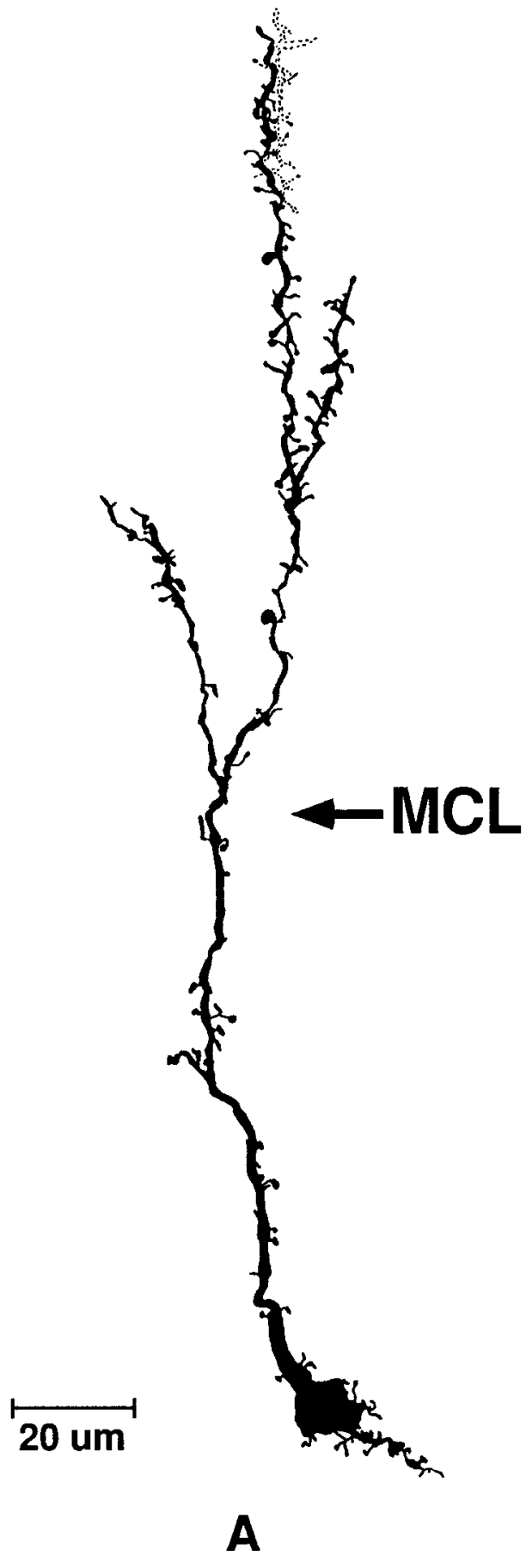

of the soma at low $R_{m}$ values than at high $R_{m}$ values. When $R_{m}$ is high, the total membrane area is important in determining the input resistance because the electronic lengths are large and thus the entire cell is more effectively reached by the current input. In contrast, at lower $R_{m}$ values, the membrane in the somal regions is the main determinant of input resistance because the electrotonic lengths are small and relatively more current leaks out across the somal membrane compared with the apical dendrites (Rall, 1977). Thus, the current inputs to the soma confirm the anatomical evidence that the three granule cells have similar total membrane areas but different distributions of the membrane between soma and dendrite.

Subunits can be defined in the steady state relative to a given spine as regions that are strongly connected by virtue of having nearly the same voltage when steady current input is delivered to that spine. As Koch et al. (1982) point out in their study of retinal ganglion cells, within such regions the possibility of nonlinear interactions among several synaptic inputs is greatest. Moreover, it may be that the full functional capacity of a dendritic arbor can be considered as the sum of its subunits. Koch et al. (1982) defined subunits as regions that were roughly equipotential and had similar decrements to the soma from all points within the subunit. These regions were defined by their steadystate transfer resistances and disappeared within the retinal ganglion cell models they studied for $K_{m}$ values above $8000 \Omega \cdot \mathrm{cm}^{2}$. With steady-state current input to individual spines, similar 


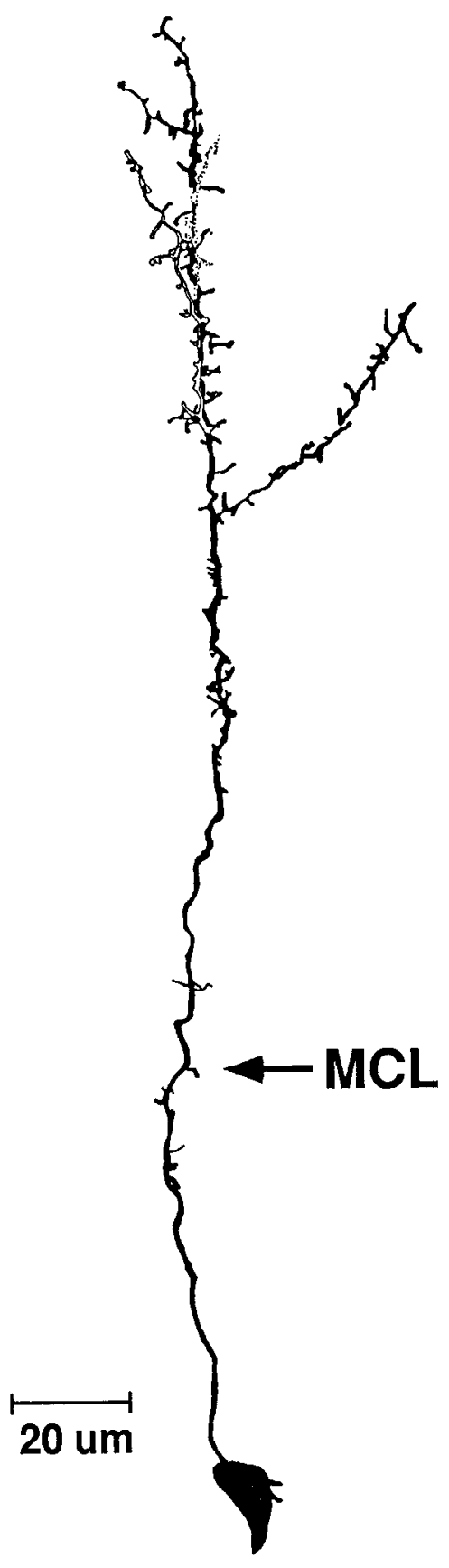

A

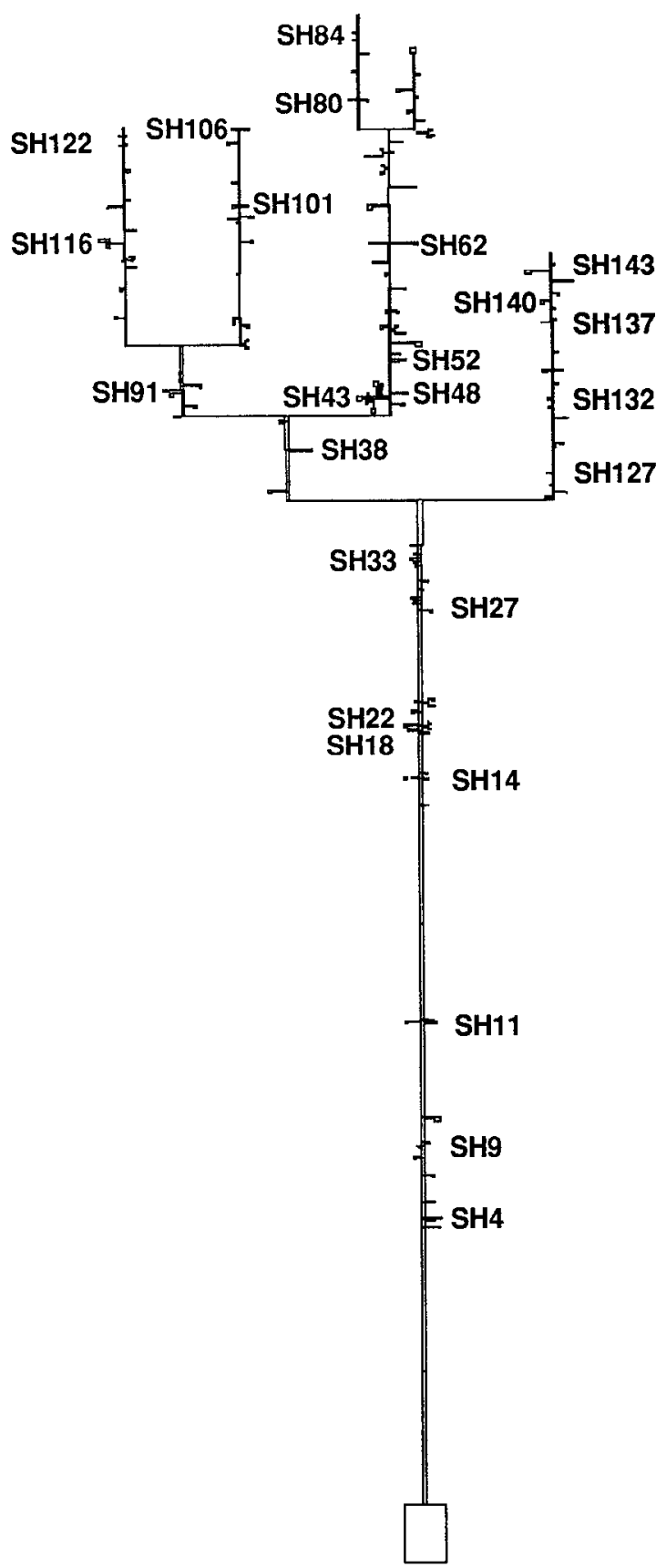

B
Figure 6. Camera lucida drawing and cable representation for $\mathrm{Gr} 3$. The cell body is below the MCL, and the dendrite bifurcates approximately halfway across the EPL and ends near the glomerular layer, making this a type III granule cell. The labeled spines in $B$ represent possible synaptic inputs to the dendritic tree. subunits can be defined for granule cell dendritic arbors. Figure 8 shows seven representative subunits in the Grl model, each subunit defined as differing by no more than $5 \%$ in voltage throughout the shaded region. These subunits enlarge and disappear for $R_{m}$ values above $100,000 \Omega \cdot \mathrm{cm}^{2}$, where input to any of the spines in Figure 4 results in the entire model cell differing in voltage by less than $5 \%$. For low $R_{m}$, the subunits are smaller than those shown in Figure 8. For low to moderate $R_{m}$, all three cell models exhibit similar variations in subunit size with differences in $R_{m}$.

Transient synaptic inputs are probably the predominant inputs to granule cell spines. There is as yet little clear evidence for the size and time course of such inputs (Carnevale and John- ston, 1982; Wilson, 1984; Coss and Perkel, 1985). Koch and Poggio (1983) have shown that steady-state synaptic inputs that are small relative to the input resistance of the spine head will resemble current inputs and that modulation of the current spread into the rest of the dendritic tree by the spine neck will not occur to any significant degree. They pointed out that changes in spine parameters will have the greatest effect on synaptic strength when the product of synaptic conductance $\left(G_{s}\right)$ and input resistance of the spine head $\left(R_{\text {in }}\right)$ is between 0.1 and 10.0:

$$
0.1<G_{s} \cdot R_{\mathrm{in}}<10.0
$$

For the present study, peak conductance inputs of 1 and $4 \mathrm{nS}$ using an $\alpha$ function with a time to peak of $0.2 \mathrm{msec}$ and a reversal 
A

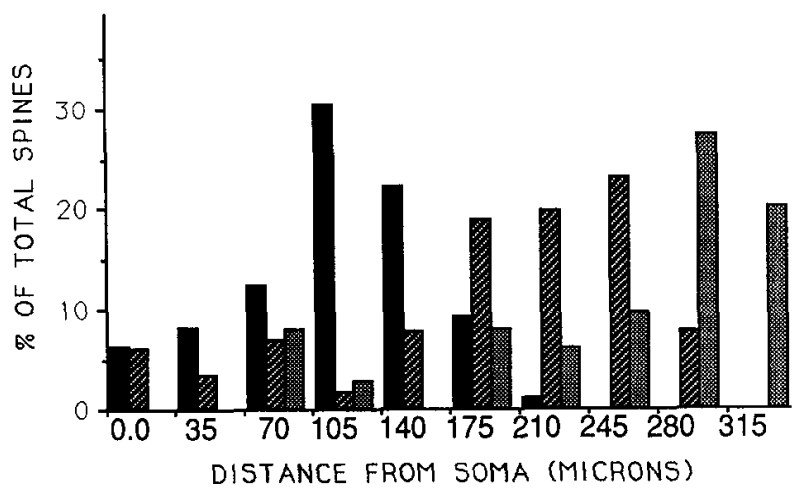

B

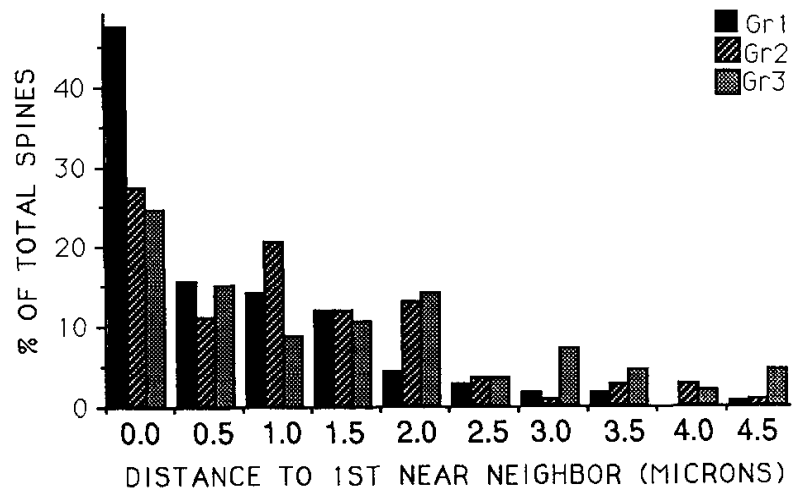

C

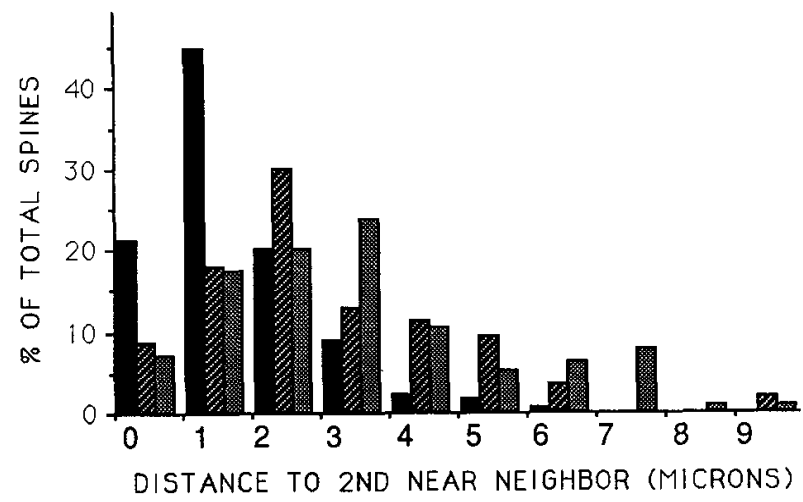

Figure 7. Histograms showing the distance from soma and the distances to the first and second near neighbors for all pedunculated spines on Gr1, Gr2, and Gr3. Notice the different distance distributions for spines on the three cells $(A)$, the relatively close distance to the first near neighbor $(B)$, and the farther distance to the second near neighbor $(C)$. potential of $70 \mathrm{mV}$ relative to rest were chosen so as to place this relationship for a subpopulation of randomly selected spines at average values of 0.5 and 2.0 , respectively (Rall, 1967). These are reasonable estimates for synaptic conductance changes and have been used in other computational studies (Shepherd and Brayton, 1979; Wilson, 1984; Coss and Perkel, 1985). Figure 9 shows the transients at selected locations in Gr2 for input to SH117 of 1 and $4 \mathrm{nS}$. Notice that, because the input is a timevarying conductance of reasonable size in series with a battery, the two sets of curves do not differ from each other by a factor of 4 , but instead by a smaller factor (Rall, 1967).

In order to assess the functional effect of the voltage in the spine head on transmitter release, some criterion must be adopted. Llinas et al. (1981) have shown in the squid giant synapse that the relation between presynaptic voltage and transmitter release is a steep sigmoidal curve. We have therefore made the simplifying assumption for granule cell spine function that, below some threshold depolarization, no transmitter will be released from a spine head, and that above that voltage, relatively little additional transmitter will be released by further increases in depolarization. If $10 \mathrm{mV}$ is arbitrarily taken as the minimum depolarization that is needed for transmitter release to begin (cf. Kusano, 1970), functional sets of granule cell spines may be defined by determining, for input to one spine, the other spines that are transiently depolarized above $10 \mathrm{mV}$ by current from the input spine head. Figure 9 shows the regions defined by $4-\mathrm{nS}$ synaptic input to the same seven spine heads as in Figure 8. Notice that three regions, SH147, SH237 and SH297, expanded in size with transient inputs, while four regions, SH97, SH167, SH207 and SH257, were smaller in size. This general result held for all three granule cells: for transient 4-nS inputs, the distal sets of spines were larger in size than the more medial and more proximal sets of spines.

Figure 10 shows the domains for 4-nS synaptic conductance changes to selected spines of Gr2. Notice that input to SH117 defined a large set of spines, while input to the nearby SH112 transiently depolarized only the input spine above $10 \mathrm{mV}$. This particular change in subset size with local spine position is also an example of the effects that can occur when the peak transient in the input spine is just above $10 \mathrm{mV}$. For SH112, the peak transient is $10.6 \mathrm{mV}$, and the nearest spine is $9.8 \mathrm{mV}$. For SH117, the peak transient in the spine head is $11.4 \mathrm{mV}$, and the nearest spine is $10.6 \mathrm{mV}$. For the rest of the subsets of spines described in Figures 10-12, local shifts in input spine head position did not have such a dramatic effect. Input to $\mathrm{SH} 157$ defined a subset of spines within the set defined by input to SH117. This emphasizes that inputs to spines below, near, and above distal branch points can influence quite different numbers of spines.

Table 1. Input resistance ( $R_{\text {in }}$ in $\mathrm{M} \Omega$ ) and time constants ( $\tau$ in msec) for all three cell models under the assumption of different membrane resistances $\left(\Omega \cdot \mathrm{cm}^{2}\right)$

\begin{tabular}{|c|c|c|c|c|c|c|}
\hline \multirow[b]{2}{*}{$\underline{R_{\mathrm{m}}}$} & \multicolumn{3}{|l|}{$R_{\text {in }}$} & \multicolumn{3}{|l|}{$\tau$} \\
\hline & Grl & Gr2 & Gr3 & Gr1 & Gr2 & Gr3 \\
\hline 1000 & 90.0 & 59.2 & 60.9 & 1.0 & 1.0 & 1.0 \\
\hline 5000 & 300.0 & 230.0 & 245.0 & 5.0 & 5.0 & 5.0 \\
\hline 10000 & 530.0 & 434.0 & 471.0 & 10.0 & 10.0 & 10.0 \\
\hline 50000 & 2300.0 & 2060.0 & 2280.0 & 50.0 & 50.0 & 50.0 \\
\hline 100000 & 4500.0 & 4060.0 & 4500.0 & 100.0 & 100.0 & 100.0 \\
\hline
\end{tabular}




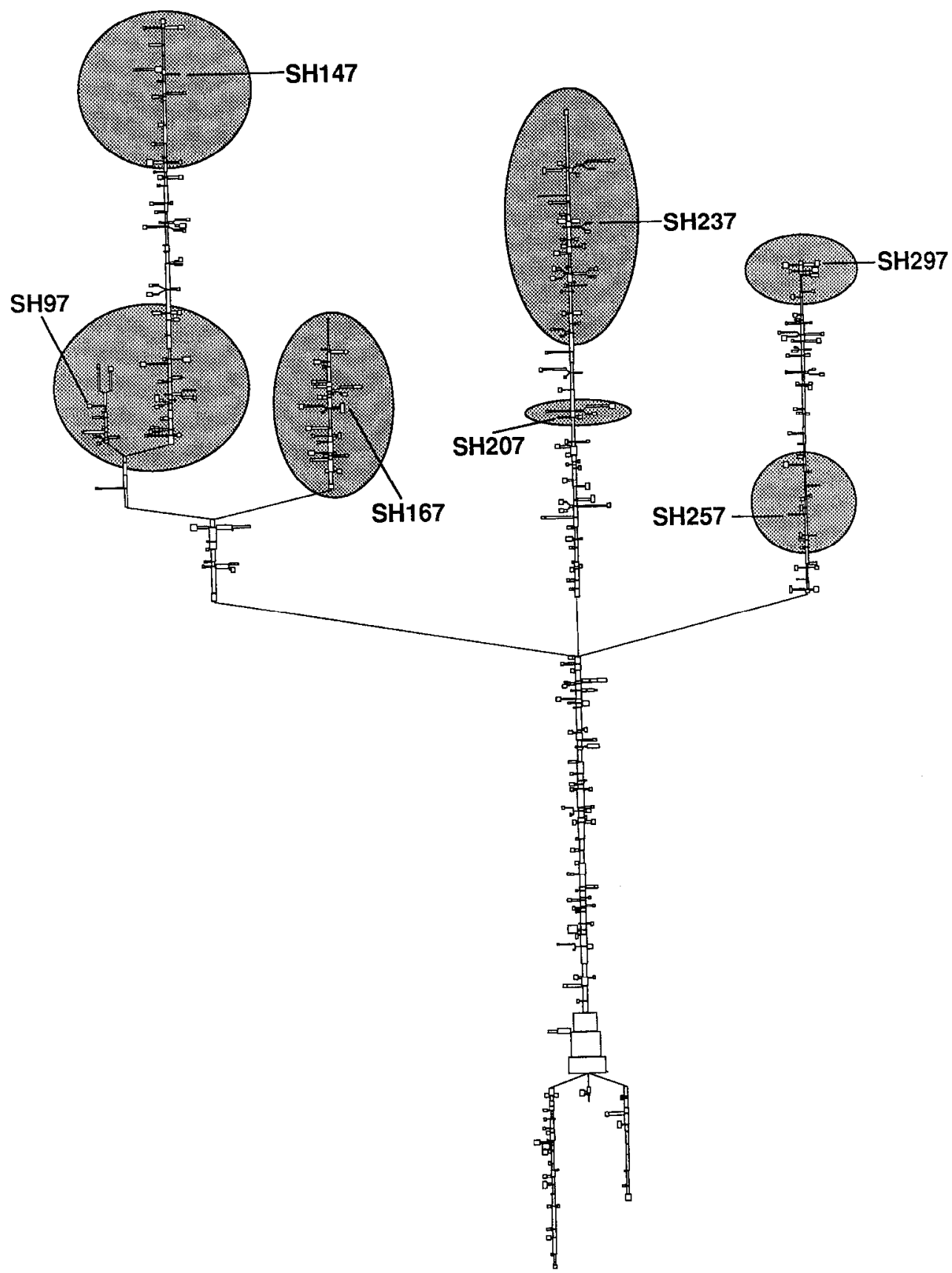

Figure 8. Steady-state subunits defined for seven spines on Grl. A subunit, illustrated by the shaded area, was defined as a region where the steadystate voltage differed by no more than $5 \%$ from the input spine. Notice the variation in size between the apical subunits and the medial subunits.
Figure 12, for Gr3, emphasizes the difference in size observed between the sets of spines above $10 \mathrm{mV}$ when the input spine is located distally versus proximally. Similar effects have been observed in idealized model neurons by analytic methods (Rall and Rinzel, 1973; Rinzel and Rall, 1974). Input to SH4, SH11, $\mathrm{SH} 14, \mathrm{SH} 22, \mathrm{SH} 38$, and SH43 produced relatively small sets of spines, while input to SH52, SH84, SH91, SH106, SH122, and SH143 produced larger sets of spines. Notice that input to SH91 at the base of the branch that contains SH122 and SH106 was able to transiently depolarize both branches, while input to either SH122 or SH106 alone depolarized only spines along their input branch.

An interesting aspect of the transient simulations was that spines that were closely related morphologically, either by being part of a multiple set of spines or by being at very nearly the same location on the dendritic arbor, had nearly identical transients in their spine heads. For example, the set of spines including SH43 on Gr3 had nearly identical voltage transients for input to any other spine location. This implies a close electrical coupling between nearby spines and within multiply branching spine structures.

To address the possibility of tissue shrinkage, some simulations were performed with the entire structure uniformly decreased in size. It is not at all clear that uniform shrinkage would occur, if the histological procedures were to produce morphological artifacts, but it is the simplest to explore computationally. If the tissue were to shrink by $20 \%$, then in general the peak transient inputs to the spine heads would increase, and the size of the subsets of spines would increase somewhat. For example, the input of $4 \mathrm{nS}$ to $\mathrm{SH} 87$ on $\mathrm{Gr} 2$ normally produces a peak 

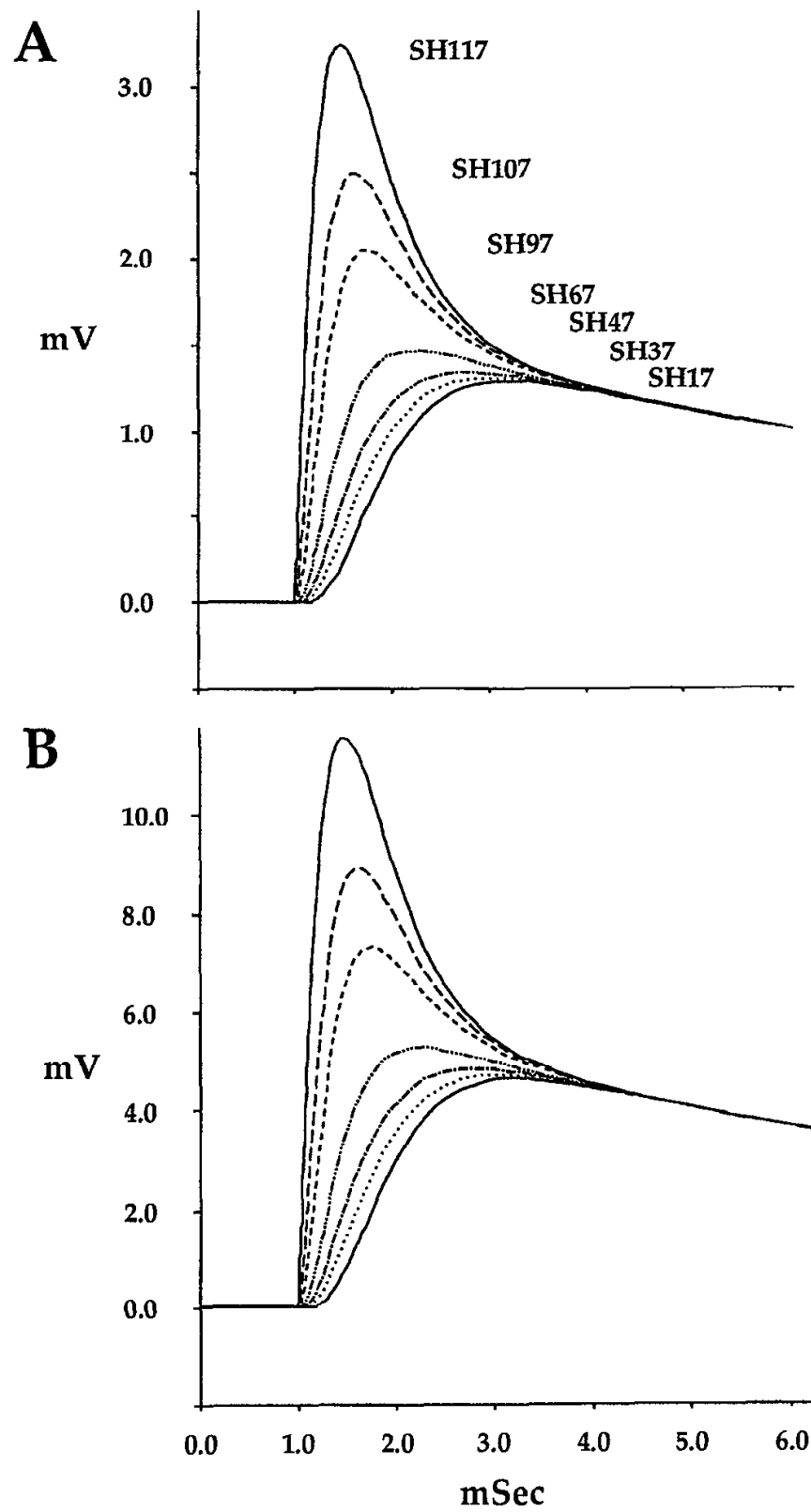

Figure 9. Transients produced in six other spines for $1-\mathrm{nS}(A)$ and 4-nS $(B)$ conductance changes to $S H 117$ on $\mathrm{Gr} 2$. Notice the relatively large decrement from the input spine to $S H 67$ and the relatively small decrement from that point on toward the soma. Because these are conductance changes and not current inputs, the two sets of transients shown in $A$ and $B$ are not related to each other by a factor of 4 .

transient of $13.7 \mathrm{mV}$ and 16 spines above $10 \mathrm{mV}$. When $\mathrm{Gr} 2$ is uniformly decreased in size by $20 \%$, the same spine has a peak transient of $17.3 \mathrm{mV}$ and 19 spines total above $10 \mathrm{mV}$.

Unlike the steady-state subunits, the domains of spines defined by transient conductance inputs did not merge into one large unit when $R_{m}$ was increased up to $100,000 \Omega \cdot \mathrm{cm}^{2}$. This is probably due to the time course of charge redistribution becoming the dominant factor over the membrane resistance in controlling the size of voltage transients throughout the dendritic tree. When small-signal AC-impedance calculations were performed for different $R_{m}$ values, it was found that, from $100 \mathrm{~Hz}$ to $10 \mathrm{kHz}$ for $R_{m}$ values of 10,000 or $100,000 \Omega \cdot \mathrm{cm}^{2}$, the im- pedance was nearly the same. For low $R_{m}$ values, the domains were smaller, but still present.

\section{Effect of spine neck changes}

Rall has suggested that small changes in the spine neck diameter and/or length could change the synaptic strength of a spine in generating transient or steady-state voltages at the soma (Rall, 1974). In the steady state, such an effect depends on the ratio of the spine neck resistance $\left(R_{\mathrm{ss}}\right)$ to the dendritic branch input resistance $\left(R_{\mathrm{bj}}\right)$ being in an operating range of $0.1-10.0$ for large conductance changes. Furthermore, because the branch input resistance increases with distance from the soma, the spine neck resistance should also increase with distance from the soma in order to maintain the spine in this operating range. For 23 spines on each of the three granule cells, $R_{\mathrm{ss}}$ and $R_{\mathrm{bi}}$ were computed. There was no correlation of $R_{\mathrm{ss}}$ with distance or with $R_{\mathrm{bj}}$. The average value of $R_{\mathrm{ss}} / R_{\mathrm{bi}}$ for all 69 spines was 0.025 . Electron microscope work has suggested that the average spine neck diameter is $0.23 \mu \mathrm{m}$ (Woolf et al., 1991). This is smaller than that measured by the light microscope. When the spine neck diamcters wcre adjusted to reflect this smaller avcrage value, the ratio $R_{\mathrm{ss}} / R_{\mathrm{bi}}$ became on average 0.072 . Because of the small volume of the spine neck and the flocculent appearance of the spine neck as seen in the electron microscope, several authors have suggested that the cytoplasmic resistivity, $R_{i}$, could be double or more the value of $70 \Omega \cdot \mathrm{cm}^{2}$ that was used for most of the present study (Koch and Poggio, 1983; Wilson, 1984; Coss and Perkel, 1985; Miller et al., 1985). When $R_{i}$ is $140 \Omega \cdot \mathrm{cm}^{2}$, the average value of $R_{\mathrm{ss}} / R_{\mathrm{bi}}$ is 0.144 , which is within the operating range defined by $R$ all.

With transient inputs of $4 \mathrm{nS}$ to four spines on each of the three granule cells, changes were made in the spine neck to increase the spine neck resistance. Fifkova and Anderson (1981) have suggested that such changes occur in such a way as to conserve the spine neck total membrane area. Several authors have adopted this convention (Koch and Poggio, 1983; Kawato et al., 1984). For that reason, a morphology factor (Mf) was defined as a constant number such that the length $(l)$ increased and the diameter $(d)$ decreased so that the total spine neck membrane area was constant:

$$
\pi \cdot l \cdot d=\pi \cdot(l \cdot M f) \cdot \frac{d}{M f},
$$

and therefore

$$
R_{l}=2 \cdot R_{i} \cdot \frac{l \cdot M f}{\pi \cdot(d / M f)^{2}}
$$

or

$$
R_{I}=(\mathrm{Mr})^{3} \cdot R_{I_{\text {orig }}},
$$

where $R_{I_{\text {orig }}}$ is the original spine neck resistance.

As seen from Equation 8, the spine neck resistance will increase as the cube of the morphology factor. Figure 13 shows the results for different morphology factors from 1.0 to 3.5 . It can be seen that for all three cells the change in the spine neck dimensions eventually decreases the size of the subsets of spines that would be above $10 \mathrm{mV}$. That the changes have to be relatively large is consistent with the argument from steady-state conditions that the spines as seen by the light microscope are outside of the ideal operating range. As the spine neck resistance increases, the voltage amplitude of the transient in the input 


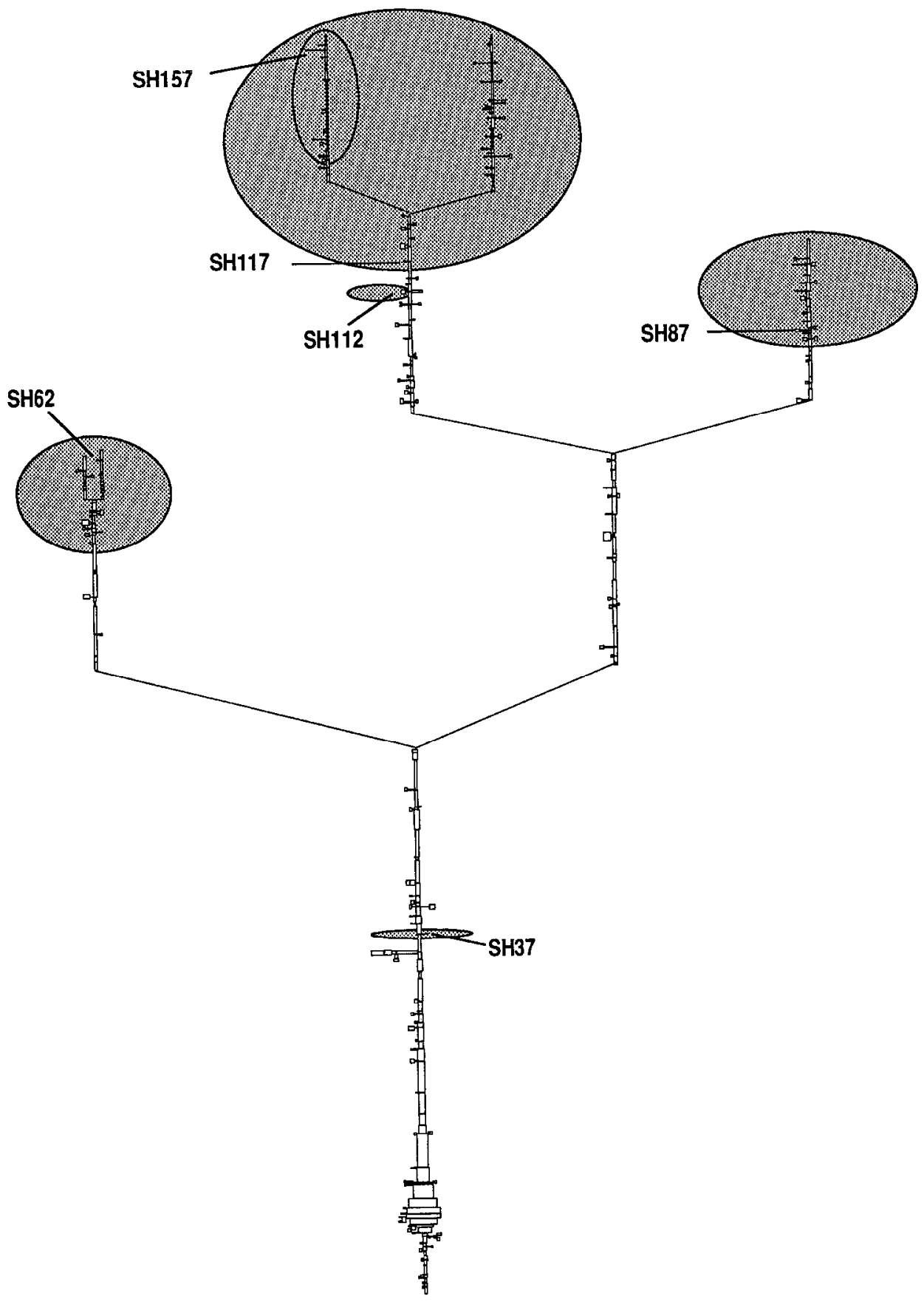

Figure 10. Subsets of spines above 10 $\mathrm{mV}$ for 4-nS transient inputs to $\mathrm{Gr} 2$ at selected locations. Notice the large difference in subset size between $\mathrm{SH} 117$ and $S H 112$ and the subset defined by input to SH157 within the subset determined by input to $S H 117$.

spine increases, and the voltage amplitude of the transients in the near neighbor spines decreases.

Figure 13 can also be used to estimate how subset size can change due to increasing spine neck resistance. For example, if the spine neck resistance were to increase by a factor of 2 (e.g., a length change without any diameter change), which would correspond to a morphology factor of 1.26 (i.e., the cube root of 2), none of the 12 spines shown for Gr1, Gr2, and Gr3 would show any significant change in subset size. However, if spine neck resistance is increased by a factor of 4 by decreasing spine neck diameter by half, to a value closer to the electron microscopic measurements (Woolf et al., 1991), spine subset size can be altered. For example, SH127 on Gr3 and SH117 on Gr2 decrease the size of their subsets by a factor of 3 and 5 , respec- tively. The other spines would have roughly similar subsets. This emphasizes the importance of a determination of the absolute value of the spine neck diameter before strong conclusions about the importance of changes in the spine morphology can be ascertained.

\section{Effect of conductance changes}

For large synaptic conductance changes, many authors have pointed out that the spine head saturates and remains at the reversal potential for the synaptic input (Koch and Poggio, 1983; Wilson, 1984; Coss and Perkel, 1985; Miller et al., 1985; Perkel and Perkel, 1985). This implies that increases in conductance beyond a certain point will have little additional effect on the size of subsets of spines. Applying the operating range defined 
Figure 11. Subsets of spines above 10 $\mathrm{mV}$ for 4-nS transient inputs to $\mathrm{Gr} 1$ at the same locations as in Figure 8. Notice that the distal spines have larger sets of spines than the more medial spines. Many of the proximal spines are not depolarized above $10 \mathrm{mV}$ for 4-nS conductance changes.

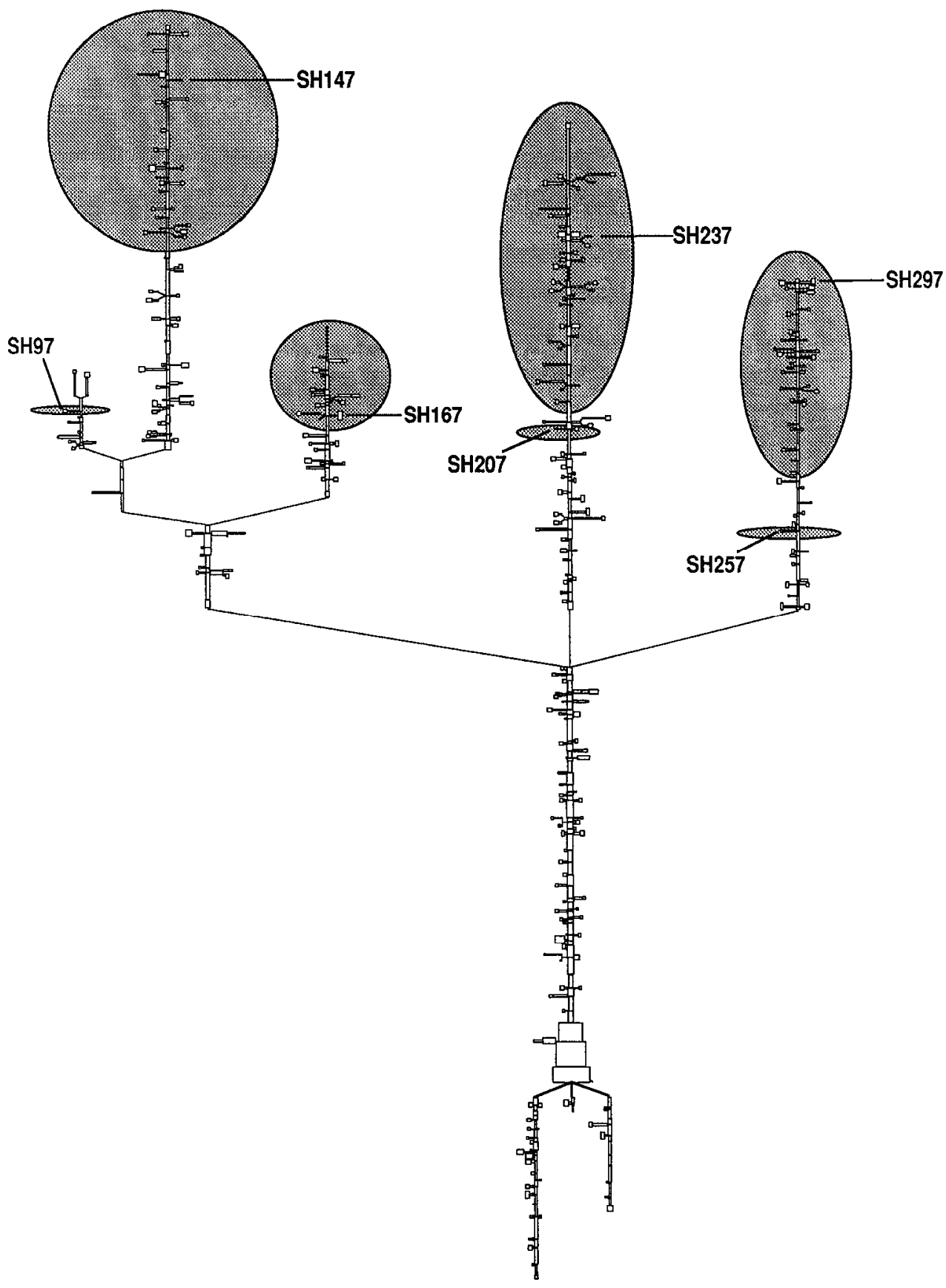

in Equation 5 for steady-state conductance inputs to several representative granule cell spines suggests that a range of inputs from 0.2 to $20.0 \mathrm{nS}$ should be considered. Figure $14 A$ shows that transient inputs to distal spines on Gr3 do saturate rapidly. For more medial and proximal spines, even strong transient conductance changes do not entirely saturate the spine head. Interestingly, the medial and proximal spines for peak conductance changes of 5-10 nS have begun to depolarize transiently the entire dendritic tree above $10 \mathrm{mV}$ and, by conductance changes of $10 \mathrm{nS}$ or more, have produced transients in almost all spines of the dendritic arbor that are above $10 \mathrm{mV}$ (see Fig. $14 B$ ). This is in contrast to the distal spines, where the large local transients in the input spine and spines nearby on the dendritic trunk decrease steeply in amplitude to transients below $10 \mathrm{mV}$ for the remainder of the dendritic arbor. For distal spines, increases in the peak conductance beyond $2 \mathrm{nS}$ do not significantly change the number of other spines above $10 \mathrm{mV}$. The shift for medial and proximal spines from a very small number of spines having transients above $10 \mathrm{mV}$ to most of the spines having transients above $10 \mathrm{mV}$ can be very abrupt. For example, increasing input to $\mathrm{SH} 27$ from 6 to $7 \mathrm{nS}$ changes the percent of spines above $10 \mathrm{mV}$ from $30 \%$ to $92 \%$. It should also be emphasized that the transient voltage gradients for distal spines can be very steep: from 50 to $60 \mathrm{mV}$ peak transient difference between the input site and the soma. This is in contrast to the medial and proximal transient peak gradients, which are often within $10 \mathrm{mV}$ over the entire tree (see also Rinzel and Rall, 1974; Rall and Segev, 1987). 


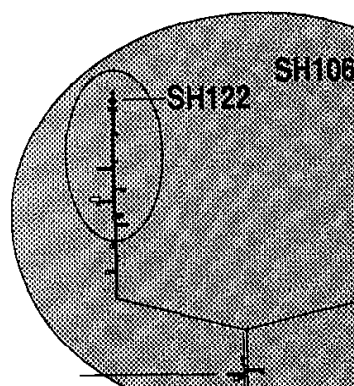

SH91
SH84
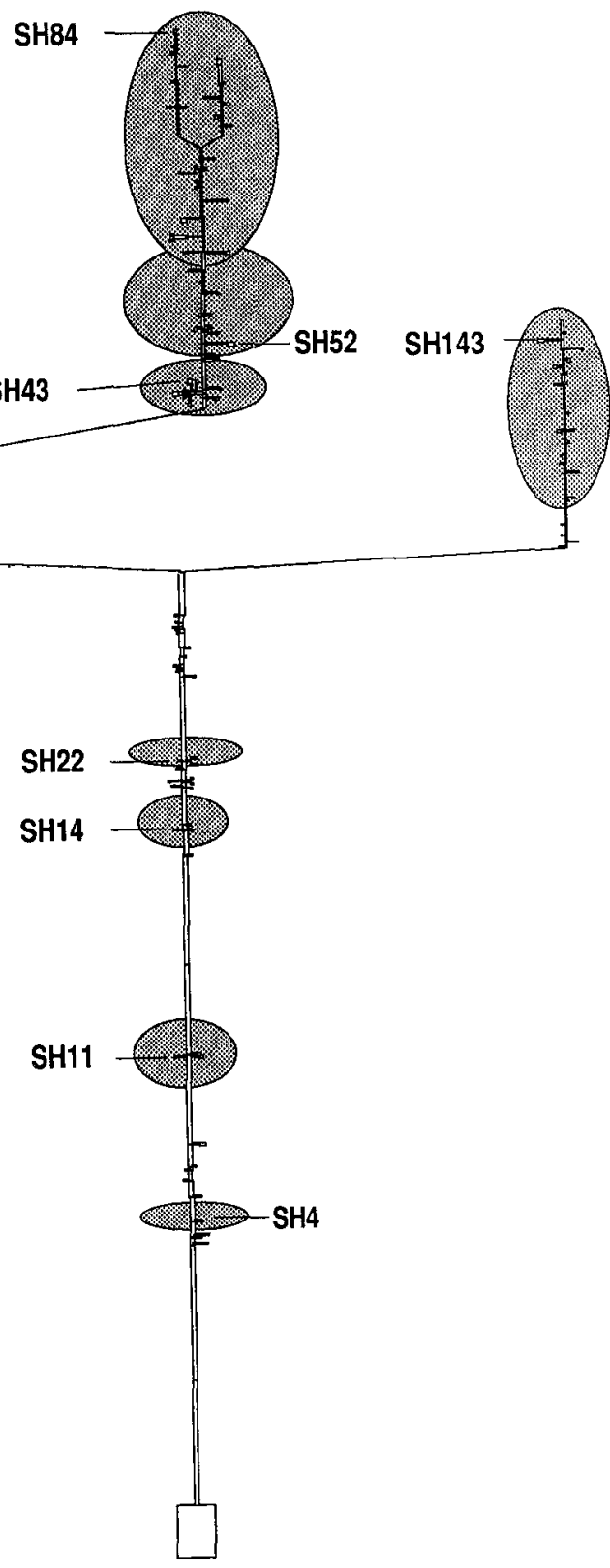

Figure 12. Subsets of spines above 10 $\mathrm{mV}$ for 4-nS transient inputs to Gr3 at selected locations. Notice the small subsets determined by proximal spine input sites and the subsets on each daughter branch determined by $S H 122$ and $S H 106$ that are included together by input to $S H Q I$.

\section{Effect of changes in the time to peak}

Wilson (1984) has shown that slowing a transient synaptic input can increase the current flowing from the input spine to the cell trunk. Figure 15 shows that this can be a significant factor in increasing the total number of spines that are above $10 \mathrm{mV}$ for transient input to spines throughout the dendritic arbor. Proximal spines can exhibit a sharp increase in the number of spines above $10 \mathrm{mV}$. For example, compare SH67 and SH187 on Gr 1 and $\mathrm{SH} 27$ and SH127 on Gr3 (Fig. 15). This effect is due to the small transients in the proximal and medial spines with inputs having a fast time to peak, so that increases in the time to peak that produce transients above $10 \mathrm{mV}$ in the input spine rapidly create large subsets of spines above $10 \mathrm{mV}$. For more apical spines, the effect is still strong, but changes occur more gradually. For example, SH84 and SH143 on Gr3 begin with a moderate number of spines above $10 \mathrm{mV}$ and gradually increase the subset size with increases in time to peak. It is important to note that cven apical input spincs with long times to peak can produce large subsets of spines. This is in contrast to the case for increased peak conductance without increased time to peak where the subset size does not increase even for large conductance changes.

\section{Multiple inputs}

Simulations were performed on all three cells to address the effect of paired inputs. The results showed that the number of spines above $10 \mathrm{mV}$ for $4-\mathrm{nS}$ inputs to two spines depended on the electrotonic distance between the two subsets that had been previously defined by separate inputs to both spines. At one extreme, if the spines were located in two separate subsets (e.g., the subsets indicated by SH84 and SH143 in Fig. 12), then simultaneous input to the two spines created two separate subsets of spines above $10 \mathrm{mV}$, and the total response was a linear 
A

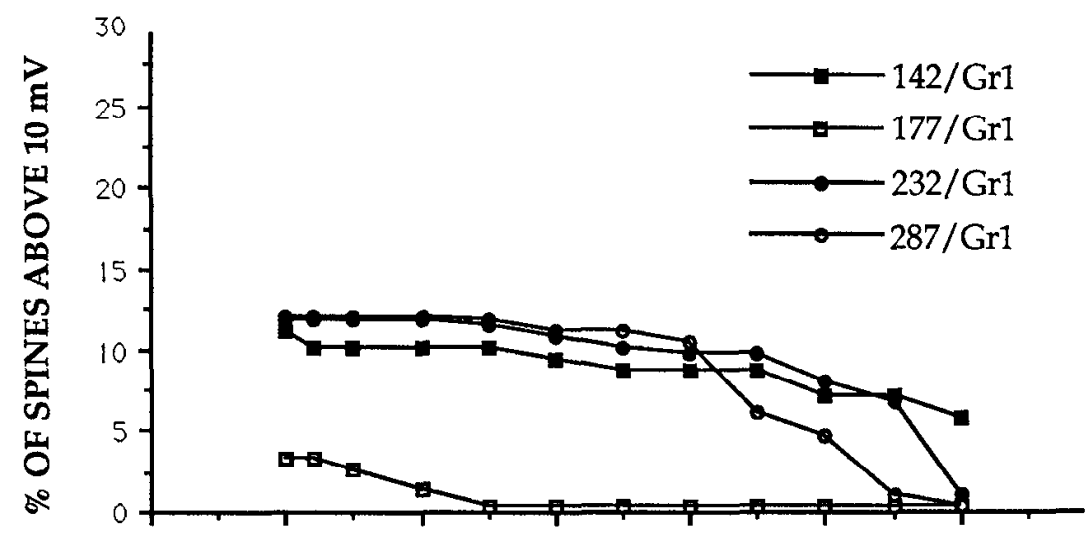

B

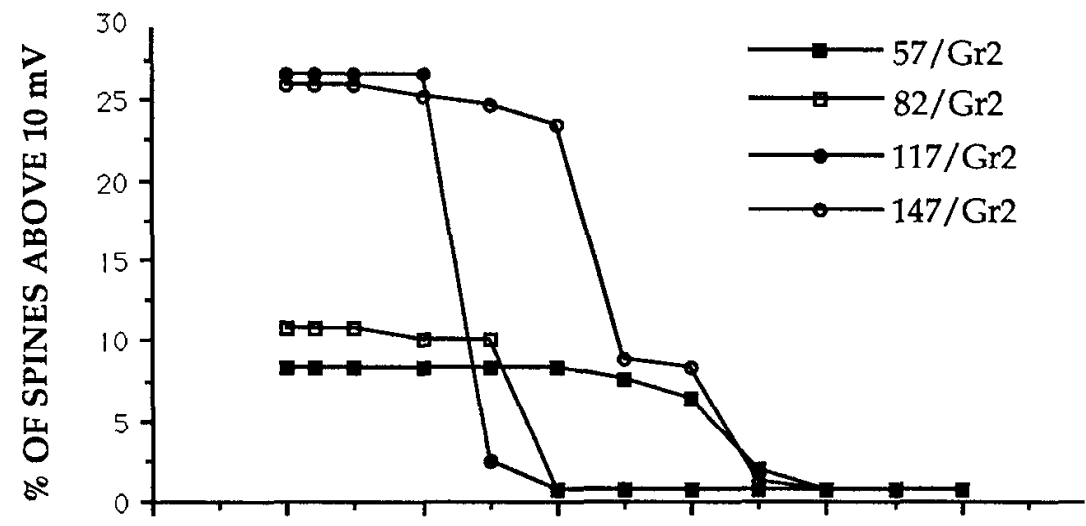

Figure 13. Changes in the size of subsets of spines with increases in spine neck resistance for transient inputs. Shown are four spines on each of the three granule cells $(A, \mathrm{Gr} 1 ; B, \mathrm{Gr} 2 ; C$, $\mathrm{Gr} 3$ ) for increases in spine neck resistance from 1.0 to 42.9 . Notice that in all cases the changes in spine neck resistance eventually decrease the size of the subset of spines.

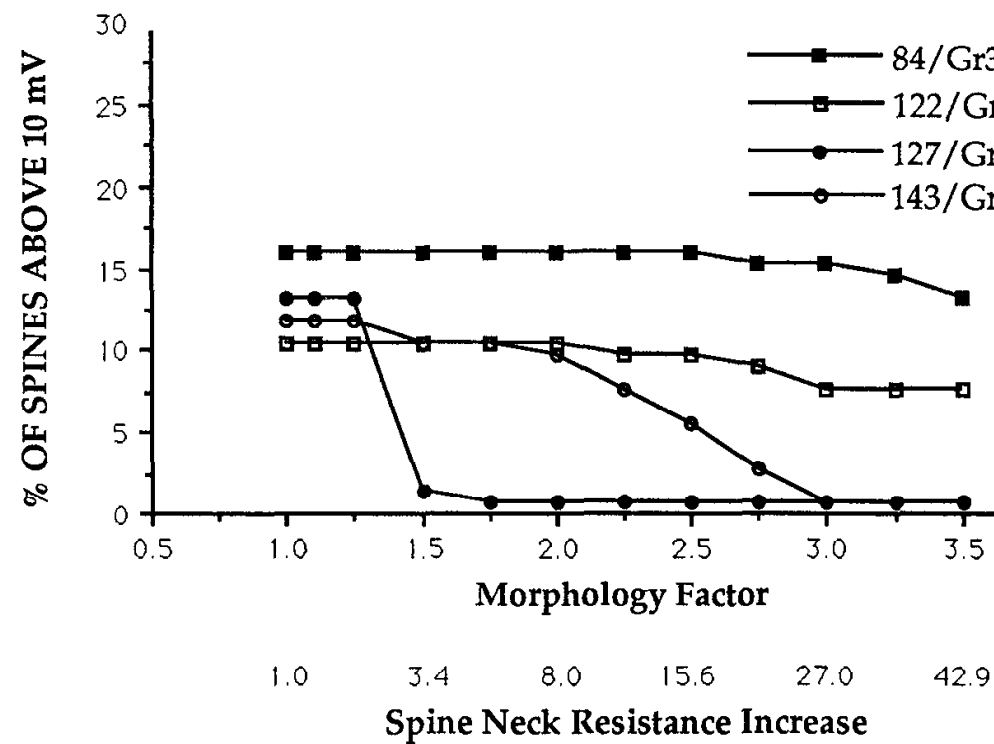

addition of activated spines. At the other extreme, when the subsets of the two spines overlapped extensively (e.g., the subsets defined by SH91 and SH106 in Fig. 12), input to both spines simultaneously increased only slightly the total number of spines that are above $10 \mathrm{mV}$. This was due to shunting interactions between the two simultaneous inputs (e.g., see Rall, 1964). When the two spines defined subsets of spines that overlapped only partially (e.g., the subsets determined by SH84 and SH52 in Fig. 12), then the resulting number of spines above $10 \mathrm{mV}$ was less than the linear addition seen when there was no overlap between subsets, but greater than the number of spines seen for the extensively overlapped case. These results are consistent with expectations from models of aspiny neurons (e.g., see Rall, 1967; Koch et al., 1982), but are only a beginning point in the 

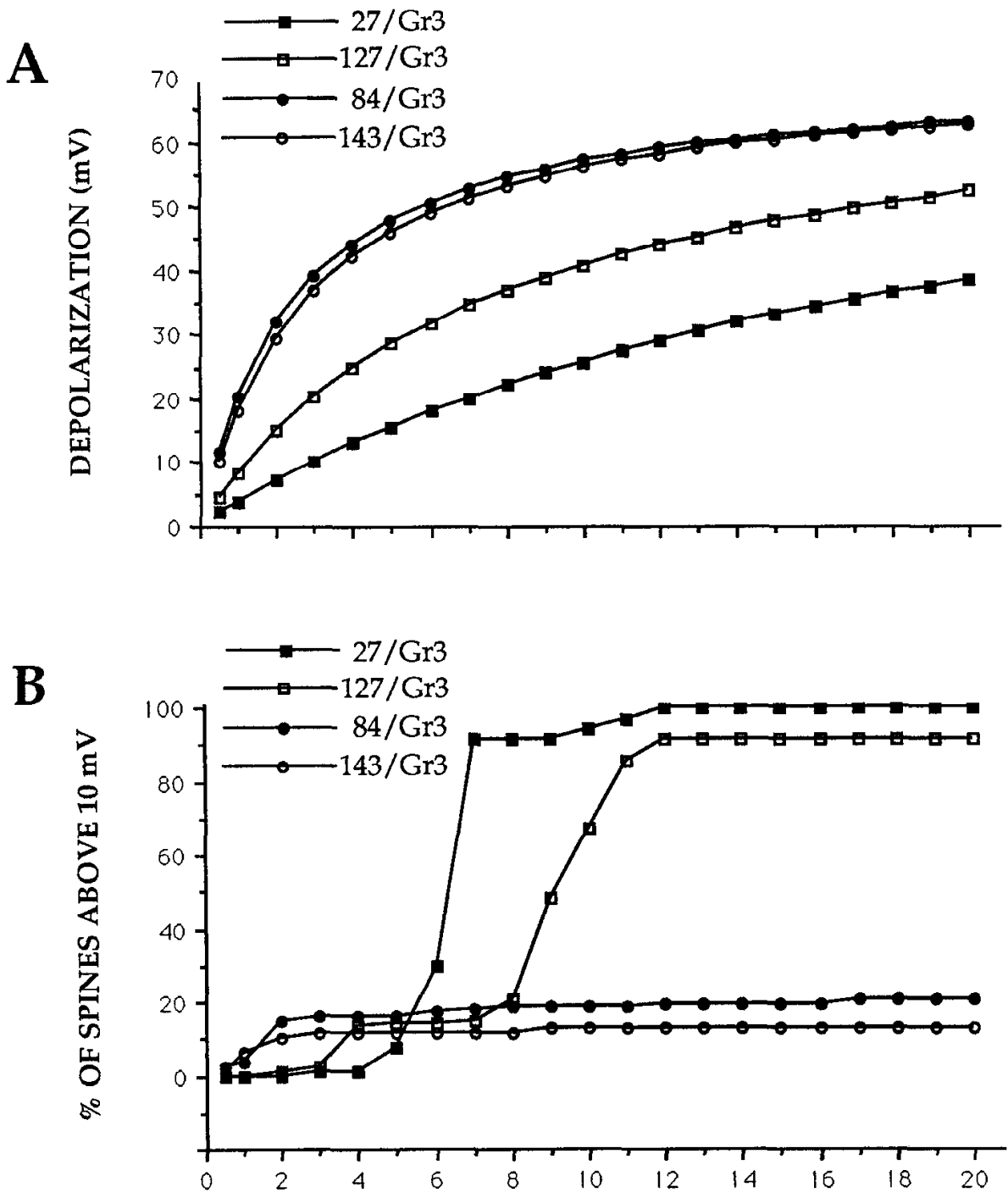

PEAK CONDUCTANCE CHANGE (nS)

\begin{abstract}
Figure 14. $A$ shows the peak transients produced in four different spine heads on Gr3 for transient conductances varying from 0.5 to $20 \mathrm{nS}$. Notice that the distal SH143 and SH84 have saturated, while the medial and proximal $S H 127$ and $S H 27$ have not yet saturated. $B$ shows that the subsets of spines defined by inputs to distal spines rapidly become stable with increases in conductance. This is in contrast to medial and proximal spines, which undergo a sudden shift from small subsets of spines above $10 \mathrm{mV}$ to very large subsets of spines above $10 \mathrm{mV}$ as the conductance level is increased.
\end{abstract}

exploration of the complex interactions that may occur between multiple inputs.

\section{Discussion}

The results in these computational models of granule cells demonstrate the importance of the anatomical location of the input spine in determining the effect of a particular synaptic conductance. Distal spine heads see large voltage transients for small input conductance changes that decrement steeply in amplitude to small transients beyond the dendritic branch containing the input spine head. For example, a 4-nS conductance change to an apical input spine will produce a large fraction of spines in the input dendritic branch above $10 \mathrm{mV}$. In contrast, proximal spines require much larger conductance changes for even moderate depolarizations that decay slowly as they spread to neighboring spines. For example, a 4-nS conductance change to a spine near the soma will probably not produce transients above $10 \mathrm{mV}$ in any spine. The density of spines is, in general, much greater distally than proximally. The total number of spines in a subset will then depend on the local density of spines as well as the location of the input site in the dendritic arbor.
As the input conductance varied in the model, the groups of activated spines varied in size depending on anatomical location. The distal spines increased their subset size rapidly following small changes in the peak transient conductance and then only slowly changed their subset size with larger conductance levels. The proximal spines did not respond to conductance increases with subsets of any appreciable size until much larger changes were applied, and then they rapidly produced very large subsets of spines above $10 \mathrm{mV}$. This implies that, for maximum effectiveness of each spine, different sizes of conductance change should be applied to distal as compared to proximal spines.

The time to peak of the input conductance was found to be a major factor in the size of a subset of spines for all locations in the dendritic arbor. For a 4-nS conductance input with a time to peak of $1 \mathrm{msec}$ or longer, very large subsets of spines resulted for spines at all locations in the dendritic arbor. This is a reflection of the shift from a dominant capacitative input impedance at the spine to a steady-state situation. Thus, for steadystate inputs, the voltage decrement between the input site and other sites is reduced, and significant numbers of other spines can be above $10 \mathrm{mV}$ for input to one spine. This implies that 
A

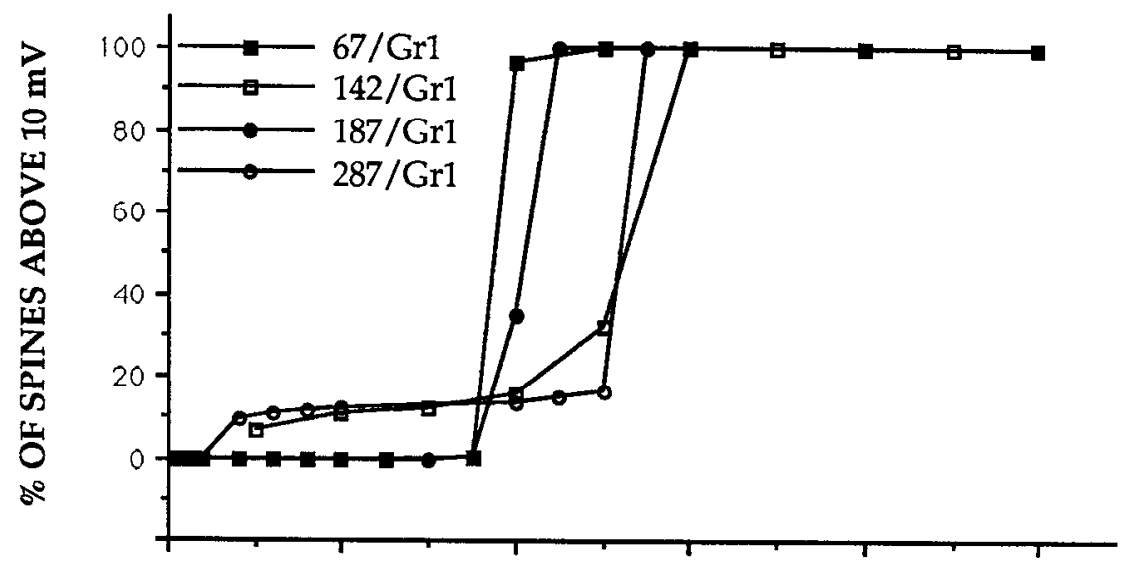

Figure 15. Increases in the time to peak of the synaptic $\alpha$ function input significantly influenced the size of the subsets of spines on all three granule cells $(A, \mathrm{Gr} 1 ; B, \mathrm{Gr} 2 ; C, \mathrm{Gr} 3)$. Notice that for distal spines this effect was gradual and required sizeable increases in the time to peak before much change was observed. This is in contrast to the more medial and proximal spines, where large shifts in subset size occurred over a small range of change in the time to peak.

B

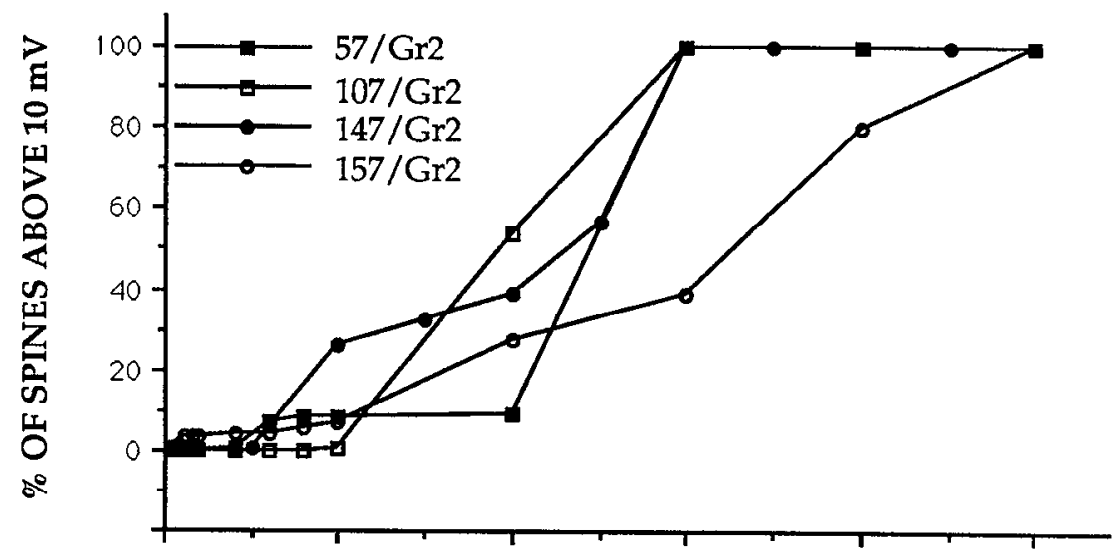

C

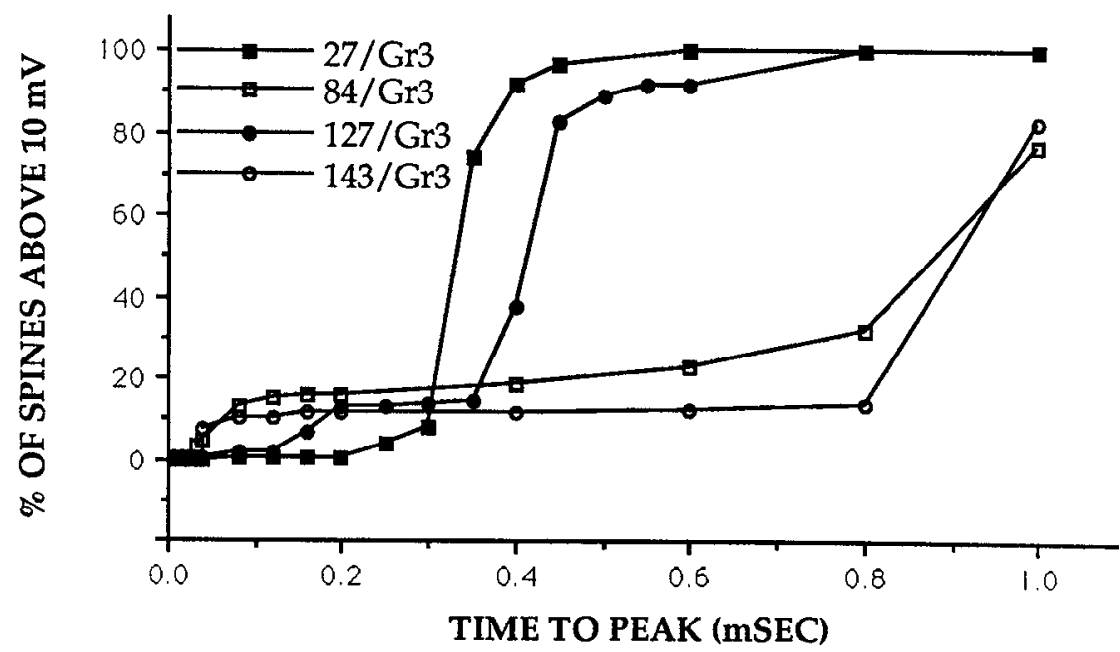

for granule cell spines an important functional variable may be changes in the time course of the input. Distal spines were least sensitive to this variable in terms of subset size. For proximal spines the shift to larger subsets of spines occurred for smaller values of the time to peak. This suggests that the optimal time to peak for granule cell spines (defined as the time at which small changes can make a large difference in subset size) will vary with the anatomical location of the spine.
Several groups have reported changes in spine neck dimensions with learning (Fifkova and Van Harreveld, 1977; Coss and Globus, 1978; Fifkova and Anderson, 1981; Brandon and Coss, 1982; Rausch and Scheich, 1982) or development (Schuz, 1986; Burgess et al., 1982). There have also been reports of changes in granule cell spine number and dimensions with odor imprinting in ferrets (Apfelbach and Weiler, 1985; Apfelbach, 1986; Rehn et al., 1988). Consistent with a suggestion by Crick 
(1982) that rapid changes in spine neck morphology may occur, several groups have reported the finding of actin in spines (Fifkova and Delay, 1982; Katsumaru et al., 1982; Caceres et al., 1983). The present computational results show that changes in the spine neck morphology could have an effect on the size of subsets of spines throughout the dendritic arbor of the granule cell. However, the changes needed for the effect to occur were relatively large (see also I Iarris and Stcvens, 1988, 1989). This may be because it is difficult to estimate from the light microscope the diameter of the spine neck (Wilson et al., 1983). Furthermore, it is possible that the spine apparatus or some other cytoplasmic organelle may significantly increase the resistivity of the spine neck (Koch and Poggio, 1983; Landis and Reese, 1983; Wilson et al., 1983; Landis et al., 1987). This is especially true of the granule cell spine, where mitochondria are often found in the spine neck and the spine head (Shepherd and Greer, 1988; Woolf et al., 1991).

The value of $R_{m}$ continues to be a matter of speculation, with patch-clamp results consistently yielding higher values than intracellular recordings (Firestein and Werblin, 1987; Coleman and Miller, 1989). In general, higher $R_{m}$ values produce larger depolarizations and smaller steady-state decrements throughout the dendritic arbor than do lower $R_{m}$ values. Lower $R_{m}$ values decrease $R_{\mathrm{bi}}$ and so increase the ratio of $R_{\mathrm{ss}} / R_{\mathrm{bi}}$, implying that granule cell spines would be closer to Rall's (1974) operating range for low $R_{m}$ values than for higher $R_{m}$ values. Because of the large combined capacitative impedance of all the other spines and the dendritic arbor at the input spine for rapid inputs, increases in $R_{m}$ for transient inputs do not imply that the entire dendritic arbor is depolarized above an arbitrary value. However, for higher $R_{m}$, increases in the time to peak of the synaptic input would be even more effective, because in the steady state the entire tree is strongly depolarized for input to any spine.

The morphological finding of small groups of spines, either as multiple-branched elements or as relatively closely spaced individual spines, implies that some spines may be very sensitive to electrical events in their neighboring spines. This implies that two spines at the same dendritic location will always both inhibit or not inhibit the mitral or tufted cell secondary dendrites to which they are connected at the same time. This could be an important mechanism for insuring that small numbers of local secondary dendrites always receive temporally coordinated inhibition.

Single inputs to granule cell spines probably do not occur in temporal isolation in vivo. However, the findings from paired inputs in our computations indicate that the results for single inputs may be generalized. If the spines under consideration are not part of the same functional unit when studied with single inputs, then inputs given to them at the same time will most likely produce functionally independent regions of activity within the granule cell tree. In contrast, if the inputs belong to the same functional unit for single inputs, then simultaneous inputs to both will not significantly shift the subset size. For overlap between subsets of spines, the results will be between these two extremes. These findings from paired inputs can only begin to explore the complex naturc of multiple inputs. However, it does suggest that activity in a granule cell tree can be considered as the sum of the activities in each region comprising the tree.

Several authors have shown that granule cells can generate action potentials (Mori and Kishi, 1982; Wellis and Scott, 1989). Wellis and Scott found odor responses to granule cells that varied from the firing of action potentials to long- or short-lasting
EPSPs to inhibition (Wellis and Scott, 1989). Although the functional significance of action potentials in granule cells is not known, it is important to consider their effect on the spines. When active membrane in the models was sited at the granule cell soma and current injected to bring the membrane above threshold, the entire dendritic arbor could be depolarized above $10 \mathrm{mV}$. This implies that centrifugal afferents as well as recurrent axonal collaterals from mitral and tufted cells may sufficiently excite some granule cells to initiate action potentials and cause release of inhibitory transmitter from the entire population of spines (Mori, 1987). Furthermore, for very large nearly simultaneous inputs to spines throughout the granule cell, an action potential could be initiated at the soma, further stimulating inhibitory output from all spines in the granule cell arbor.

The number of granule cell spines that are contacted by a given mitral or tufted cell is unknown. However, the ratio of granule cells to mitral and tufted cells $(\approx 100-200: 1)$, the orientation of the secondary dendrites of mitral and tufted cells tangentially in the EPL, and the radial orientation of the granule cell processes imply that a given mitral/tufted cell may contact only a small number of spines on any given granule cell. It appears reasonable from our recent evidence to suggest that the average number of such contacts is near one (Woolf et al., 1991). With that assumption, the numbers of spines that are above threshold for transmitter release from any given input reflect directly the number of mitral or tufted cells that would receive inhibition from that granule cell. Because subsets of spines above threshold tend to be geometrically close together in the models, it appears reasonable to suggest they are contacting secondary dendrites of mitral and tufted cells that are also spatially nearby. The local sets of spines could then be pictured as a mechanism for localizing inhibition to secondary dendrites of mitral and tufted cells that run closely together. If all spines throughout the cell are active, inhibition would be delivered to mitral and tufted cells that are throughout either the entire EPL (type I granule cell), the lower EPL (type II granule cell), or the upper EPL (type III granule cell) without any selection of mitral and tufted cells that are spatially clustered. This consideration suggests that parallel microcircuits at the level of both sets of granule cell spines and entire granule cells can be involved in processing olfactory information.

In conclusion, the finding in computational models that isolated subsets of spines can function independently, coupled with the anatomical arrangement of the olfactory bulb, implies that inhibition can be morphologically restricted to groups of mitral and tufted cell secondary dendrites. Changes in spine neck resistance or input time course or magnitude could then influence the size of the subsets of spines and allow further control over the extent of inhibition. These findings increase the potential functional complexity of granule cells: they may act at times as whole cellular units (e.g., when action potentials are fired in the cell soma) and at other times as many independent inhibitory units giving localized inhibition at various locations within the EPL.

\section{References}

Apfelbach R (1986) Imprinting on prey odours in ferrets (Mustela putorius f. furo 1.) and its neural correlates. Behav Pro 12:363-381.

Apfelbach R, Weiler E (1985) Olfactory deprivation enhances normal spine loss in the olfactory bulb of developing ferrets. Neurosci Lett 62:169-173.

Brandon JG, Coss RG (1982) Rapid dendritic spine stem shortening 
during one-trial learning: the honeybee's first orientation flight. Brain Res 252:51-61.

Burgess JW, Monachello MP, McGinn MD (1982) Early development of spiny neurons in fish and mouse: morphometric measures of dendritic spine formation pattern. Dev Brain Res 4:465-472.

Caceres A, Payne MR, Binder LI, Steward O (1983) Immunocytochemical localization of actin and microtubule-associated protein MAP2 in dendritic spines. Proc Natl Acad Sci USA 80:1738-1742.

Carnevale NT, Johnston D (1982) Electrophysiological characterization of remote chemical synapses. J Neurophysiol 47:606-621.

Carnevale NT, Woolf TB, Shepherd GM (1990) Neuron simulations with SABER. J Neurosci Methods 33:135-148.

Coleman PA, Miller RF (1989) Measurement of passive membrane parameters with whole-cell recording from neurons in the intact amphibian retina. J Neurophysiol 61:218-230.

Coss RG, Globus A (1978) Spine stems on tectal interneurons in jewel fish are shortened by social stimulation. Science 200:787-790.

Coss RG, Perkel DH (1985) The function of dendritic spines: a review of theoretical issues. Behav Neural Biol 44:151-185.

Crick F (1982) Do dendritic spines twitch? Trends Neurosci 5:44-46.

Fifkova E, Anderson CL (1981) Stimulation-induced changes in dimensions of stalks of dendritic spines in the dentate molecular layer. Exp Neurol 74:621-627

Fifkova E, Delay RJ (1982) Cytoplasmic actin in neuronal processes as a possible mediator of synaptic plasticity. J Cell Biol 95:345-350.

Fifkova E, Van Harreveld A (1977) Long-lasting morphological changes in dendritic spines of dentate granular cells following stimulation of the entorhinal area. J Neurocytol 6:211-230.

Firestein S, Werblin FS (1987) Gated currents in isolated olfactory receptor neurons of the larval tiger salamander. Proc Natl Acad Sci USA 84:6292-6296.

Greer CA (1987) Golgi analyses of dendritic organization among denervated olfactory bulb granule cells. J Comp Neurol 257:442-452.

Harris KM, Stevens JK (1988) Dendritic spines of rat cerebellar purkinje cells: serial electron microscopy with reference to their biophysical characteristics. J Neurosci 8:4455-4469.

Harris KM, Stevens JK (1989) Dendritic spines of CAl pyramidal cells in the rat hippocampus: serial electron microscopy with reference to their biophysical characteristics. J Neurosci 9:2982-2997.

Jackowski A, Parnavelas JG, Lieberman AR (1978) The reciprocal synapse in the external plexiform layer of the mammalian olfactory bulb. Brain Res 159:17-28.

Jahr CE, Nicoll RA (1982) An intracellular analysis of dendrodendritic inhibition in the turtle in vitro olfactory bulb. J Physiol (Lond) 326: 213-234.

Katsumaru H, Murakamu F, Tsukahara N (1982) Actin filaments in dendritic spines of red nucleus neurons demonstrated by immunoferritin localization and heavy meromyosin binding. Biomed Res 3: $337-340$

Kawato M, Hamaguchi T, Murakami F, Tsukahara N (1984) Quantitative analysis of electrical properties of dendritic spines. Biol $\mathrm{Cy}$ bern 50:447-454.

Koch C, Poggio T (1983) A theoretical analysis of electrical properties of spines. Proc R Soc Lond [Biol] 21 8:455-477.

Koch C, Poggio T, Torre V (1982) Retinal ganglion cells: a functional interpretation of dendritic morphology. Philos Trans R Soc Lond [Biol] 298:227-264.

Kusano K (1970) Influence of ionic environment on the relationship between pre- and postsynaptic potentials. J Neurobiol 1:435-457.

Landis DM, Reese TS (1983) Cytoplasmic organization in cerebellar dendritic spines. J Cell Biol 97:1169-1178.

Landis DM, Weinstein LA, Reese TS (1987) Substructure in the postsynaptic density of Purkinje cell dendritic spines revealed by rapid freezing and etching. Synapse 1:552-558.

Llinas R, Steinberg IZ, Walton K (1981) Relationship between presynaptic calcium current and postsynaptic potential in squid giant synapse. Biophys J 33:323-352.

Miller JP, Rall W, Rinzel J (1985) Synaptic amplification by active membrane in dendritic spines. Brain Res 325:325-330.

Mori K (1987) Membrane and synaptic properties of identified neu- rons in the olfactory bulb. Prog Neurobiol 29:275-320.

Mori K, Kishi K (1982) The morphology and physiology of the granule cells in the rabbit olfactory bulb revealed by intracellular recording and HRP injection. Brain Res 247:129-133.

Mori K, Nowycky MC, Shepherd GM (1984) Synaptic excitatory and inhibitory interactions at distal dendritic sites on mitral cells in the isolated turtle olfactory bulb. J Neurosci 4:2291-2296.

Perkel DH, Perkel DJ (1985) Dendritic spines: role of active membrane in modulating synaptic efficacy. Brain Res 325:331-335.

Price JL, Powell TPS (1970a) The morphology of the granule cells of the olfactory bulb. J Cell Sci 7:91-123.

Price JL, Powell TPS (1970b) The synaptology of the granule cells of the olfactory bulb. J Cell Sci 7:125-155.

Rall W (1964) Theoretical significance of dendritic trees for neuronal input-output relations. In: Neural theory and modeling (Reiss $R$, ed) pp 73-97. Stanford, California: Stanford University Press.

Rall W (1967) Distinguishing theoretical synaptic potentials computed for different soma-dendritic distributions of synaptic input. J Neurophysiol 30:1138-1168.

Rall W (1974) Dendritic spines, synaptic potency and neuronal plasticity. In: Cellular mechanisms subserving changes in neuronal activity (Woody CD, Brown KA, Crow TJ, Knispel JD, eds), pp 13-21. Los Angeles: University of California.

Rall W (1977) Core conductory theory and cable properties of neurons. In: Handbook of physiology (Kandel ER, ed), pp 39-97. Bethesda, MD: American Physiological Society.

Rall W, Rinzel J (1973) Branch input resistance and steady attenuation for input to one branch of a dendritic neuron model. Biophys J 13: $648-688$

Rall W, Segev I (1987) Functional possibilities for synapses on dendrites and on dendritic spines. In: Synaptic function (Edelman GM, Gall GE, Cowan WM, eds), pp 605-636. New York: Ncuroscience Research Foundation/Wiley.

Rall W, Shepherd GM, Reese TS, Brightman MW (1966) Dendrodendritic synaptic pathway for inhibition in the olfactory bulb. Exp Neurol 14:44-56.

Rausch-G, Scheich H (1982) Dendritic spine loss and enlargement during maturation of the speech control system in the mynah bird (Gracula religiosa). Neurosci Lett 29:129-133.

Rehn B, Panhuber H, Laing DG, Breipohl W (1988) Spine density on olfactory granule cell dendrites is reduced in rats reared in a restricted olfactory environment. Dev Brain Res 40:143-147.

Riley J (1979) A reliable Golgi-Kopsch modification. Brain Res Bull 3:127-129.

Rinzel J, Rall W (1974) Transient response in a dendritic neuron model for current injected at one branch. Biophys J 14:759-790.

Schuz A (1986) Comparison between the dimensions of dendritic spines in the cerebral cortex of newborn and adult guinea pigs. J Comp Neurol 244:277-285.

Segev I, Fleshman JW, Miller JP, Bunow B (1985) Modeling the electrical behavior of anatomically complex neurons using a network analysis program: passive membrane. Biol Cybern 53:27-40.

Shepherd GM, Brayton RK (1979) Computer simulation of a dendrodendritic synaptic for self- and lateral-inhibition in the olfactory bulb. Brain Res 175:377-382.

Shepherd GM, Greer CA (1988) The dendritic spine: adaptations of structure and function for different types of synaptic integration. In: Intrinsic determinants of neuronal form and function (Lasek RJ, Black MM, eds), pp 245-262. New York: Liss.

Wellis DP, Scott JW (1989) Odor-induced responses of rat olfactory bulb granule cells. Int Soc Olfaction Taste 10:48.

Wilson CJ (1984) Passive cable properties of dendritic spines and spiny neurons. J Neurosci 4:281-297.

Wilson CJ, Groves PM, Kitai ST, Linder JC (1983) Three-dimensional structure of dendritic spines in the rat neostriatum. J Neurosci 3:383398.

Woolf TB, Shepherd GM, Greer CA (1991) The geometry and connectivity of dendrodendritic microcircuits in the olfactory bulb. Synapse, in press. 